\title{
The $\mathrm{SH} 3$ and cysteine-rich domain 3 (Stac3) gene is important to growth, fiber composition, and calcium release from the sarcoplasmic reticulum in postnatal skeletal muscle
}

\author{
Xiaofei Cong ${ }^{1}$, Jonathan Doering ${ }^{2}$, Davi A. G. Mazala ${ }^{3}$ Eva R. Chin ${ }^{3}$, Robert W. Grange ${ }^{2}$ and Honglin Jiang ${ }^{\text {** }}$
}

\begin{abstract}
Background: The $\mathrm{SH} 3$ and cysteine-rich domain 3 (Stac3) gene is specifically expressed in the skeletal muscle. Stac3 knockout mice die perinatally. In this study, we determined the potential role of Stac3 in postnatal skeletal muscle growth, fiber composition, and contraction by generating conditional Stac3 knockout mice.

Methods: We disrupted the Stac3 gene in 4-week-old male mice using the Flp-FRT and tamoxifen-inducible Cre-loxP systems.

Results: RT-qPCR and western blotting analyses of the limb muscles of target mice indicated that nearly all Stac3 mRNA and more than $70 \%$ of STAC3 protein were deleted 4 weeks after tamoxifen injection. Postnatal Stac3 deletion inhibited body and limb muscle mass gains. Histological staining and gene expression analyses revealed that postnatal Stac3 deletion decreased the size of myofibers and increased the percentage of myofibers containing centralized nuclei, with no effect on the total myofiber number. Grip strength and grip time tests indicated that postnatal Stac3 deletion decreased limb muscle strength in mice. Muscle contractile tests revealed that postnatal Stac3 deletion reduced electrostimulation-induced but not the ryanodine receptor agonist caffeine-induced maximal force output in the limb muscles. Calcium imaging analysis of single flexor digitorum brevis myofibers indicated that postnatal Stac3 deletion reduced electrostimulation- but not caffeine-induced calcium release from the sarcoplasmic reticulum.
\end{abstract}

Conclusions: This study demonstrates that STAC3 is important to myofiber hypertrophy, myofiber-type composition, contraction, and excitation-induced calcium release from the sarcoplasmic reticulum in the postnatal skeletal muscle.

Key words: Skeletal muscle, Hypertrophy, Fiber type, Calcium release

\section{Background}

The Stac3 gene, which encodes a protein containing Src homology 3 and cysteine-rich domains, is expressed specifically in the skeletal muscle [1]. STAC3 has been recently identified as a novel regulator of embryonic skeletal muscle development and contraction. Stac3 knockout mice die at birth $[1,2]$. Most of the muscle fibers in newborn Stac3 knockout mice contain centralized nuclei and disorganized myofibrils [1].

\footnotetext{
* Correspondence: hojiang@vt.edu

'Department of Animal and Poultry Sciences, Virginia Tech, Blacksburg, VA, USA

Full list of author information is available at the end of the article
}

The skeletal muscles from Stac3-deleted mouse fetuses do not contract, and this is suggested to be due to defective excitation-contraction (EC) coupling [2]. A role of STAC3 in EC coupling is further supported by immunoprecipitation data from zebrafish that suggests STAC3 interacts with the dihydropyridine receptors (DHPR) and the ryanodine receptors (RYR) [3] and immunohistochemical data from mice that indicates STAC3 co-localizes with DHPR at the T-tubules [2]. A more recent study demonstrates that STAC3 is essential 
for trafficking of the major subunit of DHPR, DHPR $\alpha 1$, also known as Cav1.1 and CACNA1S, into cell membranes [4]. In vitro studies suggest that STAC3 might be involved in myoblast differentiation [5, 6]. Mutations in the human Stac3 gene have been linked to two congenital myopathies, Native American myopathy [3] and King-Denborough syndrome [7].

In this study, we determined the potential role of STAC3 in postnatal skeletal muscle growth, fiber composition, and contraction. We disrupted the Stac3 gene in 4-week-old mice through the Flp-FRT and Cre-loxP systems $[8,9]$. Our study demonstrates that STAC3 is important to fiber hypertrophy, fiber-type composition, muscle contraction, and electrostimulation-induced calcium release from the sarcoplasmic reticulum in the postnatal skeletal muscle.

\section{Methods}

\section{Generation of conditional Stac3 knockout mice}

The generation of heterozygous Stac3 mutant mice $\left(\mathrm{Stac}^{+/-}{ }^{-)}\right.$has been described [1]. The mutant Stac3 allele was inserted with a trapping cassette (SA-Bgeo-pA) flanked by two flippase (Flp) recombinase target sites (flippase recognition target, FRT) between exons 1 and 2 and two Cre recombinase target sites (loxP) that flanked exons 2 to 5 . Transgenic mice that expressed a Flp recombinase $\left(T g^{F l p}\right)$ driven by the human beta actin promoter [B6.Cg-Tg(ACTFLPe)9205Dym/J] and transgenic mice $\left(\mathrm{Tg}^{\mathrm{Cre}}\right)$ that carried a tamoxifen-inducible Cre recombinase driven by the chicken beta actin promoter/ enhancer coupled with the cytomegalovirus immediateearly enhancer [B6.Cg- $\left.\mathrm{Tg}\left(\mathrm{CAG}-\mathrm{cre} / \mathrm{Esr} 1^{*}\right) 5 \mathrm{Amc} / \mathrm{J}\right]$ were purchased from the Jackson Laboratory (Bar Harbor, ME) [10]. When purchased, these transgenic mice had been backcrossed onto the C57BL/6J background for at least five generations. A $\operatorname{Stac}^{+/-}$mouse was mated to a $\mathrm{Tg}^{\mathrm{Flp}}$ mouse to generate offspring $\left(\operatorname{Stac}^{+/ f l}\right)$ in which the mutant Stac3 allele was converted to a pre-conditioned wild-type allele. Two $\operatorname{Stac}^{+f f l}$ mice were mated to generate $\operatorname{Stac} 3^{f l / f l}$ mice in which both Stac3 alleles were converted to the pre-conditioned alleles. A Stac $3^{\text {fllfl }}$ mouse was crossed with a $\mathrm{Tg}^{\mathrm{Cre}}$ mouse to generate $\mathrm{Stac3}^{+/ f l} \mathrm{Tg}^{\mathrm{Cre}}$ mice. One $\operatorname{Stac}^{+f f l} \mathrm{Tg}^{\mathrm{Cre}}$ mouse and one $\operatorname{Stac}^{\text {fllfl }}$ mouse were mated to generate $\operatorname{Stac} 3^{\text {fl/fl }} \mathrm{Tg}^{\mathrm{Cre}}$ mice. Male Stac3 $3^{f l / f l}$, $\mathrm{Stac}^{+/ f l} \mathrm{Tg}^{\mathrm{Cre}}$, and $\mathrm{Stac}^{\text {fl/fl }} \mathrm{Tg}$ Cre mice at 4 weeks of age were injected intraperitoneally with tamoxifen (SigmaAldrich, St. Louis, MO) dissolved in corn oil at a daily dose of $75 \mathrm{mg} / \mathrm{kg}$ body mass for five consecutive days to activate the transcription of the Cre transgene and hence to delete the $\operatorname{Stac}^{f l}$ allele. All mice were kept on a 12-h light/12-h dark cycle at $23^{\circ} \mathrm{C}$. Mice had ad libitum access to food (rodent diet 2918, Harlan, Indianapolis, IN) and water. All protocols involving mice were approved by the Virginia Tech Institutional Animals Care and Use Committee.

\section{Genotyping}

Mice were genotyped by PCR of genomic DNA isolated from ear notches followed by gel electrophoresis. Genomic DNA was isolated using the DNeasy Blood \& Tissue Kit (Qiagen, Hilden, Germany). Initial PCR products were confirmed by DNA sequencing. The Flp and Cre transgenes were identified using primer pairs suggested by the Jackson Laboratory. The sizes of PCR products from these two pairs of primers were expected to be 725 and $100 \mathrm{bp}$, respectively. The wild-type and trapped $S t a c 3$ alleles were identified by PCR using primers F1 and R1. These two primers amplified a 317-bp product from the wild-type Stac3 allele and a 344-bp product from the trapped Stac3 allele. The Flp-cleaved Stac3 allele $\left(\operatorname{Stac}^{f l}\right)$ was confirmed by PCR using primers F2 and R2. These two primers were designed to flank the trapping cassette to generate a 451-bp product from the $S t a c 3^{\text {fl }}$ allele, a 259-bp product from the wild-type Stac3 allele, and no product from the trapped Stac3 allele. The Cre-recombined Stac $3^{f l}$ allele $\left(\operatorname{Stac}^{f l \Delta}\right)$ was confirmed by PCR using primers F2 and R1, which amplified a 2478-bp product from the $\operatorname{Stac}^{f l}$ allele, a 2259-bp product from the wild-type Stac3 allele, and a 530 -bp product unique to the $\operatorname{Stac}^{f \Delta}$ allele. Sequences of all primers used in this study are presented in Additional file 1: Table S1.

\section{Reverse transcription-quantitative polymerase chain reaction (RT-qPCR)}

Total RNA from mouse tissue samples was extracted using the TRI reagent (Molecular Research Center, Inc., Cincinnati, $\mathrm{OH}$ ), following the manufacturer's instructions. Concentrations of RNA samples were determined using a NanoDrop 2000 Spectrophotometer (Thermo Fisher Scientific, Pittsburgh, PA). First-strand cDNA synthesis was performed using random primers and ImProm-II reverse transcriptase (Promega Corp., Madison, WI). Quantitative PCR was performed using SyberGreen PCR Master Mix (Life Technologies Corp., Carlsbad, CA) and gene-specific primers (Additional file 1: Table S1) on a CFX96 Touch Real-Time PCR Detection System (Bio-Rad Laboratories, Inc., Hercules, CA). Primers were designed using the Primer3 software (MIT, Cambridge, MA). The specificity of all primers was verified by agarose gel electrophoresis followed by DNA sequencing. The amplification efficiency of all primers was determined by analyzing the standard curve of serially diluted cDNA. The amplification efficiency of the primers used in this study ranged from 90 to $110 \%$. The relative abundance of a mRNA to $18 S$ rRNA was calculated using the $\Delta \Delta \mathrm{Ct}$ method [11].

\section{Western blotting analysis}

Mouse muscle samples were lysed in radio immunoprecipitation assay (RIPA) buffer consisting of $25 \mathrm{mM}$ 
Tris- $\mathrm{HCl}, 150 \mathrm{mM} \mathrm{NaCl}, 1$ \% NP-40, 1 \% sodium deoxycholate, $0.1 \%$ SDS, and $1 \%$ protease inhibitors (Thermo Fisher Scientific) at $4{ }^{\circ} \mathrm{C}$ for $30 \mathrm{~min}$. The lysates were centrifuged at $12,000 \times g$ for $15 \mathrm{~min}$ at $4{ }^{\circ} \mathrm{C}$. Protein concentrations in the supernatants were measured using a BCA Protein Assay Kit (Thermo Fisher Scientific). For western blotting, $30 \mu \mathrm{g}$ of total cellular protein were resolved by $10 \%$ (for STAC3) or $6 \%$ (for CACNA1S and RYR1) SDS-PAGE followed by transfer to a $0.2 \mu \mathrm{m}$ nitrocellulose membrane (Bio-Rad Laboratories). The membrane was blocked with $5 \%$ non-fat milk in TBST (20 mM Tris- $\mathrm{HCl}, 500 \mathrm{mM} \mathrm{NaCl}$, and $0.1 \%$ Tween-20) at room temperature for $1 \mathrm{~h}$ and then incubated with 1:1000 diluted primary antibody at $4{ }^{\circ} \mathrm{C}$ overnight. The membrane was then incubated with 1:20,000 diluted secondary antibody and visualized with the ODYSSEY CLx system (LI-COR Biosciences, Lincoln, NE). Following the detection of the primary target protein, the membrane was stripped in Restore Western Blot Stripping Buffer (Thermo Fisher Scientific) and re-probed with the antibody for beta tubulin (TUBB). The following primary antibodies were used: CACNA1S (1A, Thermo Fisher Scientific), RYR1 (34C, DHSB, Iowa City, IA), STAC3 (Proteintech Group, Inc., Chicago, IL), and TUBB (E7, DHSB). The following secondary antibodies were used: IRDye goat anti-mouse $800 \mathrm{CW}$ and IRDye goat anti-rabbit 800CW (LI-COR).

\section{Hematoxylin and eosin staining}

The extensor digitorum longus (EDL) and soleus (SOL) muscles from the right hindlimbs of mice were characterized. Following dissection, a 5-mm-long segment was cut from the middle of each muscle, immersed in optimal cutting temperature compound on a cork sheet, and frozen immediately in isopentane pre-cooled in liquid nitrogen. The samples were then left in a Leica CM 1800 cryostat at $-18{ }^{\circ} \mathrm{C}$ for $20 \mathrm{~min}$ for thermal adaptation. Cross-sections of $8 \mu \mathrm{m}$ were cut and mounted on Fisher Superfrost Plus slides (Thermo Fisher Scientific) for subsequent assays. Hematoxylin and eosin staining was performed as described previously [1]. Stained sections were imaged with an Eclipse TS100 microscope (Nikon Corp., Tokyo, Japan).

\section{Myosin-ATPase and nicotinamide adenine dinucleotide- tetrazolium reductase (NADH-TR) staining}

Myosin-ATPase and NADH-TR staining of the EDL and SOL sections prepared above were conducted as described previously [12]. Briefly, for myosin-ATPase staining, muscle sections were pre-incubated for $5 \mathrm{~min}$ in a sodium barbital buffer containing $20 \mathrm{mM}$ sodium barbital and $36 \mathrm{mM} \mathrm{CaCl}_{2}$ at pH 4.21 and then incubated for $55 \mathrm{~min}$ in a sodium barbital buffer containing $3.5 \mathrm{mM}$ ATP, $20 \mathrm{mM}$ sodium barbital, and $18 \mathrm{mM}$
$\mathrm{CaCl}_{2}$ at $\mathrm{pH}$ 9.45. The sections were rinsed in $1 \%$ $\mathrm{CaCl}_{2}$ for $3 \times 1 \mathrm{~min}$ and then immersed in $2 \% \mathrm{CoCl}_{2}$ for $2 \mathrm{~min}$. The sections were then stained with $1 \%$ $\left(\mathrm{NH}_{4}\right)_{2} \mathrm{~S}$ for $20 \mathrm{~s}$ followed by five rinses with $\mathrm{ddH}_{2} \mathrm{O}$. Stained sections were dehydrated in 50, 70, 80, 90, and $100 \%$ ethanol, cleared in xylene, and then mounted in 50 \% xylene and 50 \% Canada balsam (Thermo Fisher Scientific) mixture. The activity of NADH-TR in the muscle sections was determined by incubating the sections at $37{ }^{\circ} \mathrm{C}$ for $10 \mathrm{~min}$ and then with $1 \mathrm{mg} / \mathrm{ml}$ nitroblue tetrazolium and $0.4 \mathrm{mg} / \mathrm{ml} \beta$ $\mathrm{NADH}$ (Sigma-Aldrich) in $50 \mathrm{mM}$ Tris- $\mathrm{HCl}$ buffer, $\mathrm{pH} 7.3$, at $37{ }^{\circ} \mathrm{C}$ for $30 \mathrm{~min}$. After $5 \times 5 \mathrm{~min}$ washes in a graded acetone series $(30,60,90,60$, and $30 \%)$, the sections were washed with $\mathrm{ddH}_{2} \mathrm{O}$, mounted in prolong gold mounting medium (Invitrogen), cover-slipped, and imaged with an Eclipse TS100 microscope (Nikon Corp.).

\section{Grip strength and grip time tests}

Grip strength and grip time were measured weekly at approximately 9:00 a.m. Grip strength was tested using a digital mouse grip strength meter (AMETEK, Inc. Berwyn, PA). The mouse was allowed to grip a wire mesh grid with its front paws and then was gently pulled away by its tail until it released the grid. This was repeated three times, and the mouse was allowed to rest for $5 \mathrm{~min}$ between two consecutive tests. The maximum force $(\mathrm{mN})$ generated by each pull was recorded by a force transducer attached to the grid, and values from three pulls were averaged for each mouse. Grip time was determined using a coarse metal wire with a $2 \mathrm{~mm}$ diameter. The mouse was allowed to hold the wire using its front paws. The time from initial grip to release was recorded as grip time. Data from tests in which the mouse was unwilling to hold the wire and dropped off consciously were discarded. The grip time test was repeated at least three times with $5 \mathrm{~min}$ of rest between two consecutive tests. Grip time from three successful tests was averaged for each mouse. The mouse's motivational or cardiovascular status could affect the measured grip strength or time, and these statuses were not evaluated in these tests.

\section{Muscle contractile tests}

Fast-twitch EDL and slow-twitch SOL muscles were excised from euthanized mice at 8 weeks of age, i.e., 4 weeks after tamoxifen injection. The isolated muscles were incubated at $30{ }^{\circ} \mathrm{C}$ in an oxygenated $\left(95 \% \mathrm{O}_{2}\right.$ and $5 \% \mathrm{CO}_{2}$ ) physiological salt solution (PSS) as previously described [13]. Non-absorbable braided silk suture (4-0) was tied to the distal and proximal tendons at the myotendinous junctions. Muscles were then fixed between a clamp and the arm of a Dual-Mode Servomotor System 
(300B, Aurora Scientific Inc., Aurora, Ontario, Canada) at a resting tension of $1.0 \mathrm{~g}$ which was maintained by a stepper motor. One EDL muscle and one SOL muscle from the same mouse were tested under the same treatment conditions at the same time. The servomotor arm and stepper motor were controlled by Dynamic Muscle Control software (DMC Version 4.1.6, Aurora Scientific) to obtain the tension output data.

The stimulated muscle protocol consisted of three steps. In step 1, the stimulated muscles were subjected to three isometric twitches and tetani $(150 \mathrm{~Hz})$ spaced 1 min apart. In step 2, after a 10 -min quiescent period, the muscles were subjected to a force-frequency protocol at electrical stimulation frequencies of $1,30,50,80$, 100, and $150 \mathrm{~Hz}$. Stimulation frequencies were spaced $1 \mathrm{~min}$ apart and were delivered as $200-\mu$ s square wave pulses, at $20 \mathrm{~V}$. In step 3, after 5 min of rest, the stepper motor was turned off, the PSS-only buffer drained, and fresh PSS buffer containing $25 \mathrm{mM}$ caffeine was added to the EDL and SOL muscle baths. At the end of each experiment, after a 10-min washout with PSS, each muscle was gently blotted dry on a Kimwipe; muscle mass was determined to the nearest $0.1 \mathrm{mg}$ using an A-200D electronic analytical balance (Denver Instruments, Denver, $\mathrm{CO}$ ).

Tension output profiles were analyzed using the Dynamic Muscle Analysis software (DMA Version 3.2, Aurora Scientific) to determine contractile properties, including peak tension, time to peak tension (TPT), and half-relaxation time (HRT). Muscle cross-sectional area (CSA) was determined as previously described [14]. Twitch and tetanic tensions were normalized to muscle CSA to obtain twitch and tetanic stress $\left(\mathrm{mN} / \mathrm{mm}^{2}\right)$.

\section{Single myofiber isolation}

Flexor digitorum brevis (FDB) muscles were isolated from 8-week-old mice and digested in minimum essential medium (MEM) solution containing $10 \%$ fetal bovine serum (FBS), $1 \%$ penicillin-streptomycin, and $0.2 \%$ collagenase type 2 (Worthington Biochemical Corp., Lakewood, NJ) for $4 \mathrm{~h}$ at $37{ }^{\circ} \mathrm{C}$ in a tissue culture incubator $\left(5 \% \mathrm{CO}_{2}\right)$. The muscle samples were then gently triturated with plastic Pasteur pipettes into a 24-well plate with MEM solution containing $10 \%$ FBS and $1 \%$ penicillin-streptomycin. Single muscle fibers were obtained by trituration. Subsequently, fibers were maintained in MEM solution with $10 \%$ FBS at $37{ }^{\circ} \mathrm{C}$ until used for EC coupling assessment.

\section{EC coupling assessment in single myofibers}

Single muscle fibers were loaded with Fura-4F AM for 15 min. The Fura- $4 \mathrm{~F}$ ratio was measured in response to electrical stimulation as an index of $\left[\mathrm{Ca}^{2+}\right]_{\mathrm{i}}$. Fibers loaded with Fura-4F were placed in a stimulation chamber containing parallel electrodes and the chamber was positioned on a Nikon TiU microscope stage. Muscle fibers were continuously perfused with a stimulating Tyrode solution $(121.0 \mathrm{mM} \mathrm{NaCl}, 5.0 \mathrm{mM} \mathrm{KCl}$, $1.8 \mathrm{mM} \mathrm{CaCl}, 0.5 \mathrm{mM} \mathrm{MgCl}, 0.4 \mathrm{mM} \mathrm{NaH} \mathrm{PO}_{4}$, $24.0 \mathrm{mM} \mathrm{NaHCO} 3$, and $5.5 \mathrm{mM}$ glucose) with $0.2 \% \mathrm{FBS}$ [15]. This solution was bubbled with $95 \% \mathrm{O}_{2}$ and $5 \%$ $\mathrm{CO}_{2}$ to maintain a $\mathrm{pH}$ of 7.3 [15]. Levels of $\left[\mathrm{Ca}^{2+}\right]_{\mathrm{i}}$ were assessed by the Fura-4F fluorescence ratio using an IonOptix HyperSwitch system with a dual excitation, single emission filter set for Fura-4F (excitation 340 and $380 \mathrm{~nm}$; emission $510 \mathrm{~nm}$ ). Signals were captured and analyzed using the IonWizard software (IonOptix). Global Fura-4F ratio was measured in the muscle fibers using trains of stimuli at $10,30,50,70$, and $100 \mathrm{~Hz}$ for $350 \mathrm{~ms}$ with fibers resting $1 \mathrm{~min}$ between frequencies. Peak Fura-4F ratios at each frequency were determined by the average ratio in the last $100 \mathrm{~ms}$ of the $350-\mathrm{ms}$ tetanus when $\mathrm{Ca}^{2+}$ Fura-4F should be at a steady state. All single muscle fibers were evaluated at room temperature.

\section{Statistics}

Student's $t$ test was used to determine the statistical significance of the differences between two groups. ANOVA followed by Tukey's test was used to examine the statistical significance of differences between more than two groups. A difference was considered statistically significant when $P<0.05$. All data were presented as mean \pm standard error of the mean (SEM).

\section{Results}

\section{Postnatal deletion of the Stac3 gene in mice}

The original mutant Stac3 allele contained two Frt sites between exons 1 and 2 and two loxP sites that flanked exons 2 and 5 (Fig. 1a). By crossing Stac $^{+/-}$mice first with mice expressing the Flp recombinase $\left(T g^{F l p}\right)$ and then mice expressing the tamoxifen-inducible Cre recombinase $\left(\mathrm{Tg}^{\mathrm{Cre}}\right)$, we generated mice with the following genotypes: $\operatorname{Stac}^{\text {fllfl }} \mathrm{Tg}^{\text {Cre }}$, which were homozygous for the floxed Stac3 allele and carried the Cre recombinase transgene; $\operatorname{Stac}^{+f f l} \mathrm{Tg}^{\mathrm{Cre}}$, which were heterozygous for the floxed Stac3 allele and carried the Cre recombinase transgene; and $S t a c 3^{f l / f l}$, which were homozygous for the floxed Stac3 allele but did not carry the Cre recombinase transgene. We confirmed these genotypes by PCR of genomic DNA from these mice (Fig. 1a, b).

We injected male $\operatorname{Stac}^{f l / f l}$, $\operatorname{Stac}^{+f l} \mathrm{Tg}^{\mathrm{Cre}}$, and $\mathrm{Stac}^{\mathrm{fl} /}$ ${ }^{f l} \mathrm{Tg}{ }^{C r e}$ mice at 4 weeks of age with tamoxifen for five consecutive days to induce the expression of Cre recombinase (Fig. 1a). RT-qPCR analyses of the hindlimb and forelimb muscles from these mice at 8 weeks of age, i.e., 4 weeks after tamoxifen injection, revealed that Stac3 mRNA was nearly absent in $\operatorname{Stac}^{f l / f l} \mathrm{Tg}^{\mathrm{Cre}}$ mice compared to $\operatorname{Stac}^{f l / f l}$ 


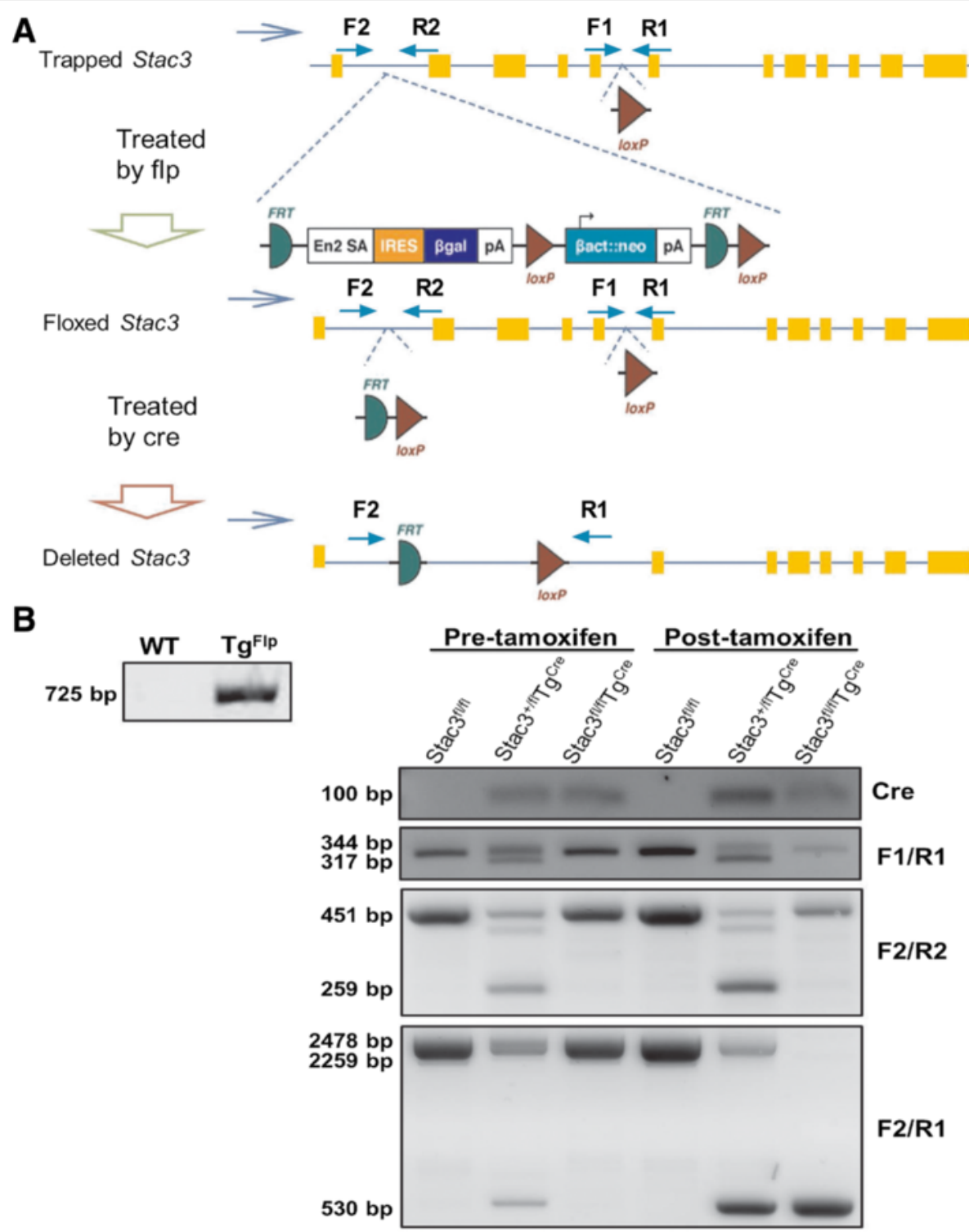

Fig. 1 Generation of conditional Stac3 knockout mice. a Schematic representation of the process of generating conditional Stac3 knockout mice. The original mutant Stac3 allele contained a "trapping cassette" between Stac3 exons 1 and 2 and a loxP site between exons 5 and 6. Crossing heterozygous Stac3 mutant mice with mice expressing the Flp recombinase caused the trapping cassette to be deleted at the two FRT sites and hence converted the mutant Stac3 allele to a floxed allele, i.e., a pre-conditional wild-type allele. Crossing mice bearing the floxed Stac3 allele with mice expressing the Cre recombinase caused exons 2 to 5 flanked by the loxP sites to be deleted and hence inactivated the Stac 3 gene. In the Cre recombinase transgenic mice used in this study, the Cre gene is located downstream of a tamoxifen-inducible chicken beta actin promotor. Arrows labeled with $F 1, R 1, F 2$, and $R 2$ indicate the locations of PCR primers for genotyping. $\mathbf{b}$ Representative gel images of genotyping. Genotypes of Stac3 $3^{f / f l}, \mathrm{StaC}^{+/ f f} \mathrm{Tg}^{\mathrm{Cre}}$, and $\mathrm{Stac} 3^{\mathrm{flff}} \mathrm{Tg} \mathrm{g}^{\mathrm{Cre}}$ mice before and 4 weeks after tamoxifen injection were identified by PCR of genomic DNA followed by gel electrophoresis. Names of PCR primers or target genes are indicated on the right of gel images and sizes of expected PCR products on the left of gel images. WT wild type

mice (Fig. 2a, $P<0.05)$. Stac3 mRNA expression in 8week-old $\mathrm{Stac}^{+/ f l} \mathrm{Tg}^{\mathrm{Cre}}$ mice was reduced by $50 \%$ compared to that in 8-week-old $\operatorname{Stac} 3^{\text {fllfl }}$ mice, but the difference was not statistically significant (Fig. 2a). Western blotting analyses revealed that STAC3 protein expression in hindlimb and forelimb muscles was reduced by more than $70 \%$ in 8-week-old $\operatorname{Stac}^{f l / f l} \mathrm{Tg}^{\mathrm{Cre}}$ mice compared to 8-week-old Stac3 ${ }^{\text {flfl }}$ mice (Fig. 2b c, $P<0.05$ ). STAC3 protein expression in the forelimb muscles of 8-week-old $\mathrm{Stac}^{+/ f l} \mathrm{Tg}^{\mathrm{Cre}}$ mice was reduced by approximately $50 \%$ compared to that in 8-week-old Stac $3^{f l f l}$ mice (Fig. 2b, c, $P<0.05)$. STAC3 protein expression in the hindlimb muscles was not different between 8-week-old $\mathrm{Stac}{ }^{+/ f l} \mathrm{Tg}$ Cre and $\operatorname{Stac}^{f l f l}$ mice (Fig. 2b, c). Overall, these analyses 

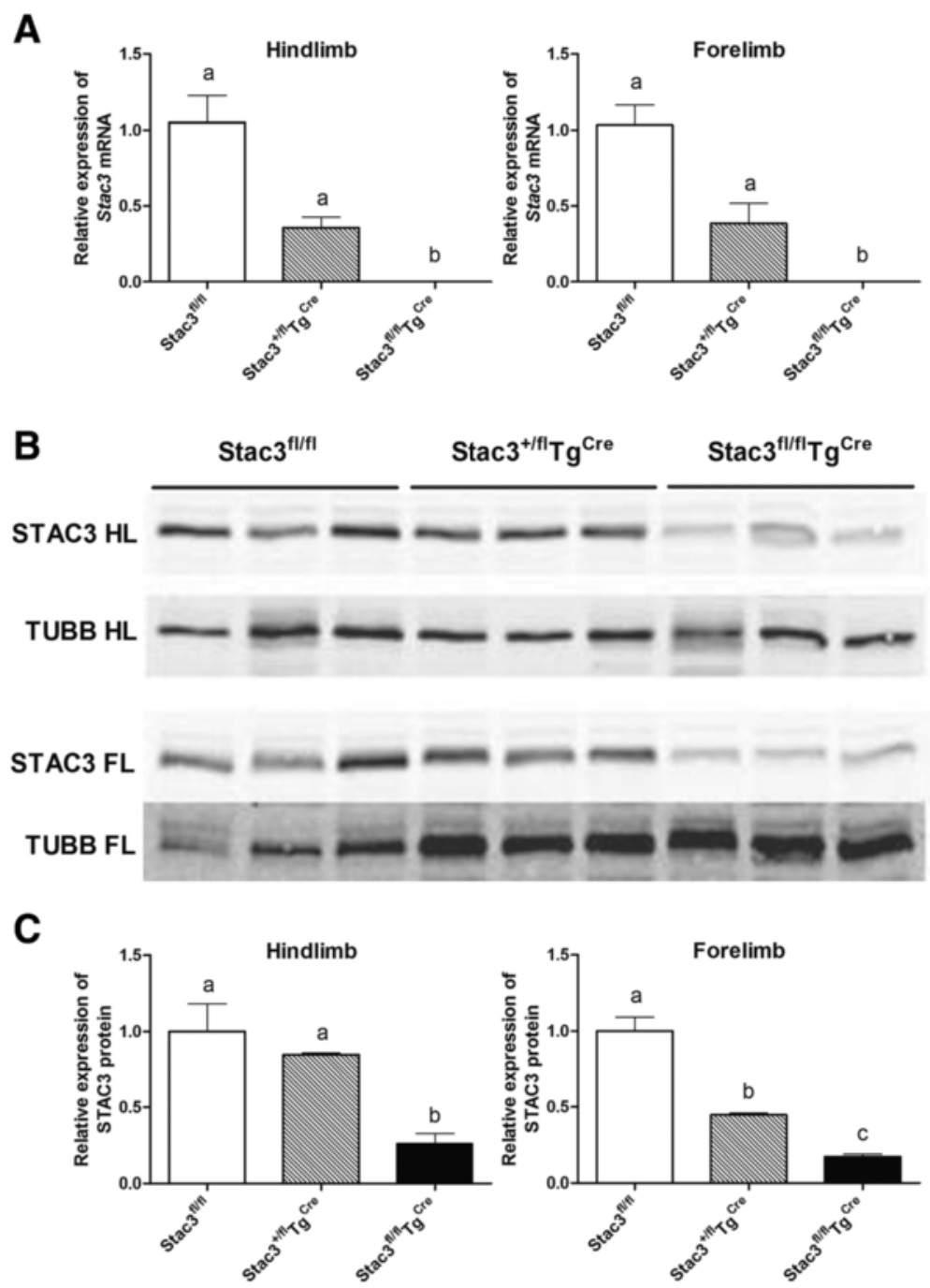

Fig. 2 Validation of Stac3 knockout. a Analysis of Stac3 mRNA expression. Stac3 mRNA in the hindlimb and forelimb muscles of Stac $3^{\text {ff/fll}}$, Stac3 ${ }^{+/ f t} T g^{\text {Cre }}$, and $\operatorname{Stac}^{\mathrm{fl} / \mathrm{TI}} \mathrm{Tg}$ (re mice at 8 weeks of age, i.e., 4 weeks after tamoxifen injection, was quantified by RT-qPCR. Bars not sharing the same letter labels are different $(P<0.05, n=4$ mice). b Images from western blotting analyses of STAC3 protein in hindlimb (HL) and forelimb (FL) skeletal muscles of

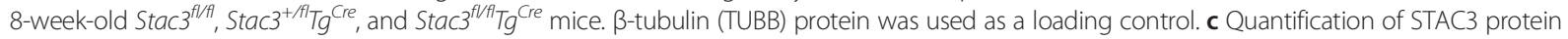
band intensity. The expression level of STAC3 protein is normalized to that of $\beta$-tubulin in the same sample. Bars not sharing the same letter labels are different $(P<0.05, n=3$ mice)

demonstrated that nearly all Stac3 mRNA and the majority of STAC3 protein were ablated by tamoxifen-induced Cre recombinase in $\operatorname{Stac}^{f l / f} \mathrm{Tg}^{\mathrm{Cre}}$ mice.

\section{Postnatal Stac3 deletion reduced body and muscle growth}

From 4 to 8 weeks of age, $\operatorname{Stac} 3^{f l f l} \mathrm{Tg}^{\mathrm{Cre}}$ mice gained approximately $2 \mathrm{~g}$ in body mass while control mice $\left(\mathrm{Stac}^{+}{ }^{+f t} \mathrm{Tg}^{\mathrm{Cre}}\right.$ and $\left.\operatorname{Stac} 3^{f l / f t}\right)$ gained approximately $5 \mathrm{~g}$ (Fig. 3a). The masses of the EDL, tibialis anterior (TA), and SOL muscles from 8-week-old $\mathrm{Stac}^{\mathrm{fl} / \mathrm{fl}} \mathrm{Tg}^{\mathrm{Cre}}$ mice were nearly $30 \%$ less than those from 8-week-old $\operatorname{Stac}^{+/ f l} \mathrm{Tg}^{\mathrm{Cre}}$ or Stac $3^{\text {fl fl }}$ mice (Fig. 3b, $P<0.05$ ). The masses of the heart and liver were not different between 8-week-old $S t a c 3^{f l / f l} \mathrm{Tg}$ Cre mice and $\operatorname{Stac}^{+/ f l} \mathrm{Tg}^{\mathrm{Cre}}$ or $\mathrm{Stac} 3^{\text {fl/fl }}$ mice (data not shown).
Neither body mass (Fig. 3a) nor individual muscle masses (Fig. 3b) was different between 4-week-old $\operatorname{Stac}^{f l / f l} \mathrm{Tg}^{\text {Cre }}$ and $\mathrm{Stac}^{+/ f l} \mathrm{Tg}^{\mathrm{Cre}}$ or $\mathrm{Stac}^{\mathrm{fl} / f l}$ mice. These data ruled out the possibility that differences in body and muscle masses between these mice at 8 weeks of age were due to differences in their initial genotypes.

\section{Postnatal Stac3 deletion decreased muscle size and} increased the number of myofibers with centralized nuclei Decreased muscle size and the presence of centralized nuclei were evident in the $\operatorname{Stac}^{f l / f l} \mathrm{Tg}^{\mathrm{Cre}}$ EDL compared to the other genotypes (Fig. 4a). Total myofiber numbers in EDL muscles of 8-week-old $\operatorname{Stac} 3^{\text {fl/fl}}, \mathrm{Stac}^{+f l} \mathrm{Tg}{ }^{\mathrm{Cre}}$, and $\operatorname{Stac}^{f l / f l} \mathrm{Tg}^{\mathrm{Cre}}$ mice did not differ (Fig. 4b). The 


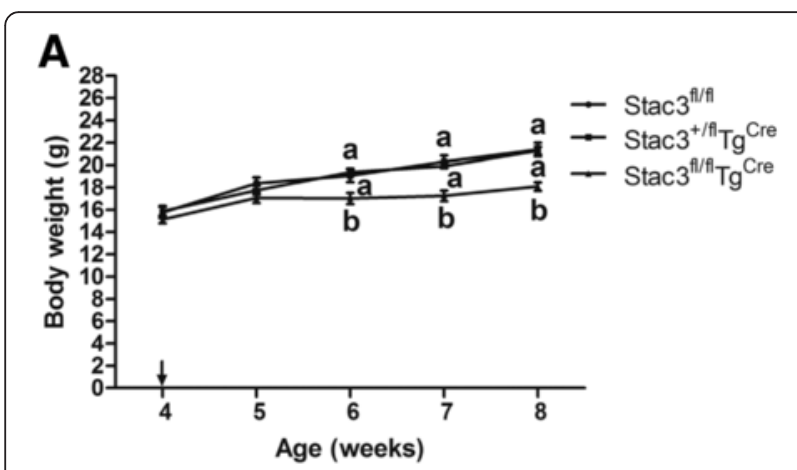

B

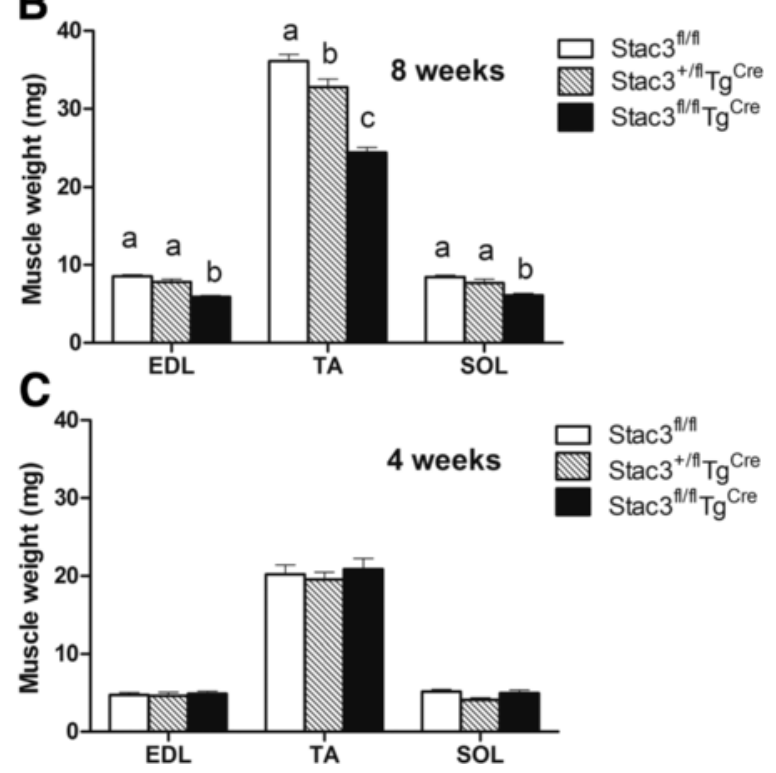

Fig. 3 Body and muscle masses of Stac3 ${ }^{f l / f l}, \operatorname{Stac}^{+/ f f} \mathrm{Tg}^{\mathrm{Cre}}$, and $S t a 3^{f f / f} \mathrm{Tg}^{\mathrm{Cre}}$ mice. a Body mass before and after tamoxifen injection. Tamoxifen injection was initiated on the first day of week 5 of age (indicated by a black arrow) and continued for 5 days. Body masses not sharing the same letter labels are different at the same age ( $P<0.05, n=4$ mice). b Masses of EDL, TA, and SOL muscles at 8 weeks of age. Bars not sharing the same letter labels are different $(P<0.05$, $n=4$ mice). $c$ Masses of EDL, TA, and SOL muscles at 4 weeks of age. The masses of these muscles were not different between 4-week-old

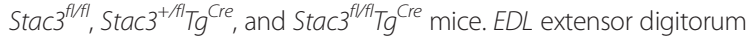
longus, TA tibialis anterior, $\mathrm{SOL}$ soleus

average CSA of EDL myofibers in 8-week-old Stac3 ${ }^{\text {fl }}$ ${ }^{f l} \mathrm{Tg}^{\mathrm{Cre}}$ mice was smaller than that in 8-week-old $S t a c 3^{+/ f l} \mathrm{Tg}^{\mathrm{Cre}}$ mice, and the latter was smaller than that in 8-week-old Stac $3^{f l f l}$ mice (Fig. 4c, P<0.05). The distribution of CSA of 8-week-old Stac $3^{f l / f l} \mathrm{Tg}^{\mathrm{Cre}}$ EDL myofibers was skewed to the left compared to that of 8-week-old $\mathrm{Stac}^{+/ f l} \mathrm{Tg}^{\mathrm{Cre}}$ or $\mathrm{Stac} 3^{f l / f l}$ EDL myofibers (Fig. 4d). The EDL muscle in 8-week-old Stac ${ }^{f l / f l} \mathrm{Tg}^{\mathrm{Cre}}$ mice contained more myofibers with centralized nuclei than that in $S t a c 3^{+/ f l} \mathrm{Tg}^{\mathrm{Cre}}$ or $S t a c 3^{\text {fl/fl }}$ mice (Fig. $4 \mathrm{e}, P<$ 0.05). Similar differences in myofiber CSA and number of myofibers with centralized nuclei were observed for the
SOL muscles between $S t a c 3^{f l / f l} \mathrm{Tg}^{\mathrm{Cre}}$ and $S t a c 3^{f l / f l}$ or ${ }_{S t a c}{ }^{+/ f l} \mathrm{Tg}^{\mathrm{Cre}}$ mice (Fig. 5a-e). However, none of these differences were observed for the EDL or SOL muscles from $S t a c 3^{f l / f l}, \mathrm{Stac}^{+/ f l} \mathrm{Tg}{ }^{\mathrm{Cre}}$, and $\mathrm{Stac}^{f l / f l} \mathrm{Tg}^{\mathrm{Cre}}$ mice at 4 weeks of age, i.e., before tamoxifen injection (Additional file 2: Figure S1 and Additional file 3: Figure S2).

\section{Postnatal Stac3 deletion increased the percentage of type I and oxidative myofibers}

Body musculature of 8-week-old $S t a c 3^{f l / f l} \mathrm{Tg}^{\mathrm{Cre}}$ mice appeared to be redder than those from 8-week-old $S t a c 3^{f l / f l}$ mice (Fig. 6). Based on myosin-ATPase staining at $\mathrm{pH}$ 4.21 (Fig. 7a), the 8-week-old Stac $^{f l / f l} \mathrm{Tg}^{\mathrm{Cre}}$ EDL muscle contained a higher percentage of type I fibers and a lower percentage of type II (IIa, b, and $x$ ) fibers than the 8-week-old Stac3 $3^{f l f l}$ or $S t a c 3^{+/ f l} \mathrm{Tg}^{\text {Cre }}$ EDL muscle (Fig. $7 \mathrm{~b}, P<0.05$ ). The percentage of type I or type II fibers was not different between the 8-week-old Stac3 ${ }^{\text {fl } / f l}$ and $\mathrm{Stac}^{+/ f l} \mathrm{Tg}^{\mathrm{Cre}}$ EDL muscles (Fig. 7b). The percentage of type I or type II myofibers was not different between the 8-week-old $\operatorname{Stac}^{\text {flffl }} \mathrm{Tg}^{\mathrm{Cre}}$ and $\mathrm{Stac}^{\mathrm{fl} / f l}$ or $\mathrm{Stac}^{+/ f l} \mathrm{Tg}$ SOL muscle (Fig. 7c). The percentage of type I or type II fibers in the EDL or the SOL muscle was not different between 4-week-old $S t a c 3^{f l / f l} \mathrm{Tg}^{\mathrm{Cre}}$ and $S t a c 3^{f l / f l}$ or Stac ${ }^{+/ f l} \mathrm{Tg}^{\text {Cre }}$ mice (Additional file 4: Figure S3). Based on NADH-TR staining (Fig. 8a), the 8-week-old $S t a c 3^{f l / f l} \mathrm{Tg}^{\mathrm{Cre}}$ EDL and SOL muscles contained higher percentages of myofibers that stained darker, meaning greater oxidative capacity, than the 8-week-old $S t a c 3^{f l / f l}$ or $\mathrm{Stac}^{+/ f l} \mathrm{Tg}^{\mathrm{Cre}} \mathrm{EDL}$ and SOL muscles (Fig. 8b, $P<0.05$ ). Neither NADH-TR staining of the EDL muscle nor that of the SOL muscle was different between 4-week-old Stac $3^{f l}$ ${ }^{f l} \mathrm{Tg}^{\mathrm{Cre}}$ and $\mathrm{Stac3}{ }^{f l f l}$ or $\mathrm{Stac3}^{+/ f l} \mathrm{Tg}^{\mathrm{Cre}}$ mice (Additional file 5: Figure S4).

\section{Postnatal Stac3 deletion increased the expression of genes marking type I fibers and developing muscle} We compared the expression levels of genes Actn3, Myh1, Myh2, Myh4, and Tnnt3 that are markers of type II myofibers and the expression levels of genes $M b, M e f 2 c, M y h 7$, Ppargc1a, and Tnnt1 that are markers of type I myofibers, in the hindlimb muscles of 8-week-old $\operatorname{Stac}^{\text {fl/fl }} \mathrm{Tg}^{\mathrm{Cre}}$, $\mathrm{Stac3}^{+/ f l} \mathrm{Tg}^{\mathrm{Cre}}$, and $\mathrm{Stac}^{\text {fl/fl }}$ mice. As shown in Table 1, four of the five type I fiber marker genes including $M y h 7$, which is the only myosin heavy chain gene expressed in type I fibers, were expressed at greater levels in 8-weekold $S t a c 3^{f l / f l} \mathrm{Tg}^{\mathrm{Cre}}$ than in 8-week-old $S t a c 3^{f l / f l}$ or Stac3 ${ }^{+/ f l} \mathrm{Tg}{ }^{\mathrm{Cr}}$ mice; two of the five type II fiber marker genes including Myh4, the predominant myosin heavy chain expressed in type II fibers, were expressed at lower levels in 8-week-old Stac3 $3^{f l / f l} T_{g}^{C r e}$ than in 8-week-old Stac3 $3^{f l f l}$ or $S t a c 3^{+/ f l} \mathrm{Tg}^{\mathrm{Cre}}$ mice. Among the five type II fiber marker genes analyzed, expression of Actn3 mRNA was greater in 8-week-old Stac $3^{f l / f l} \mathrm{Tg}^{\mathrm{Cre}}$ than in 8-week-old 


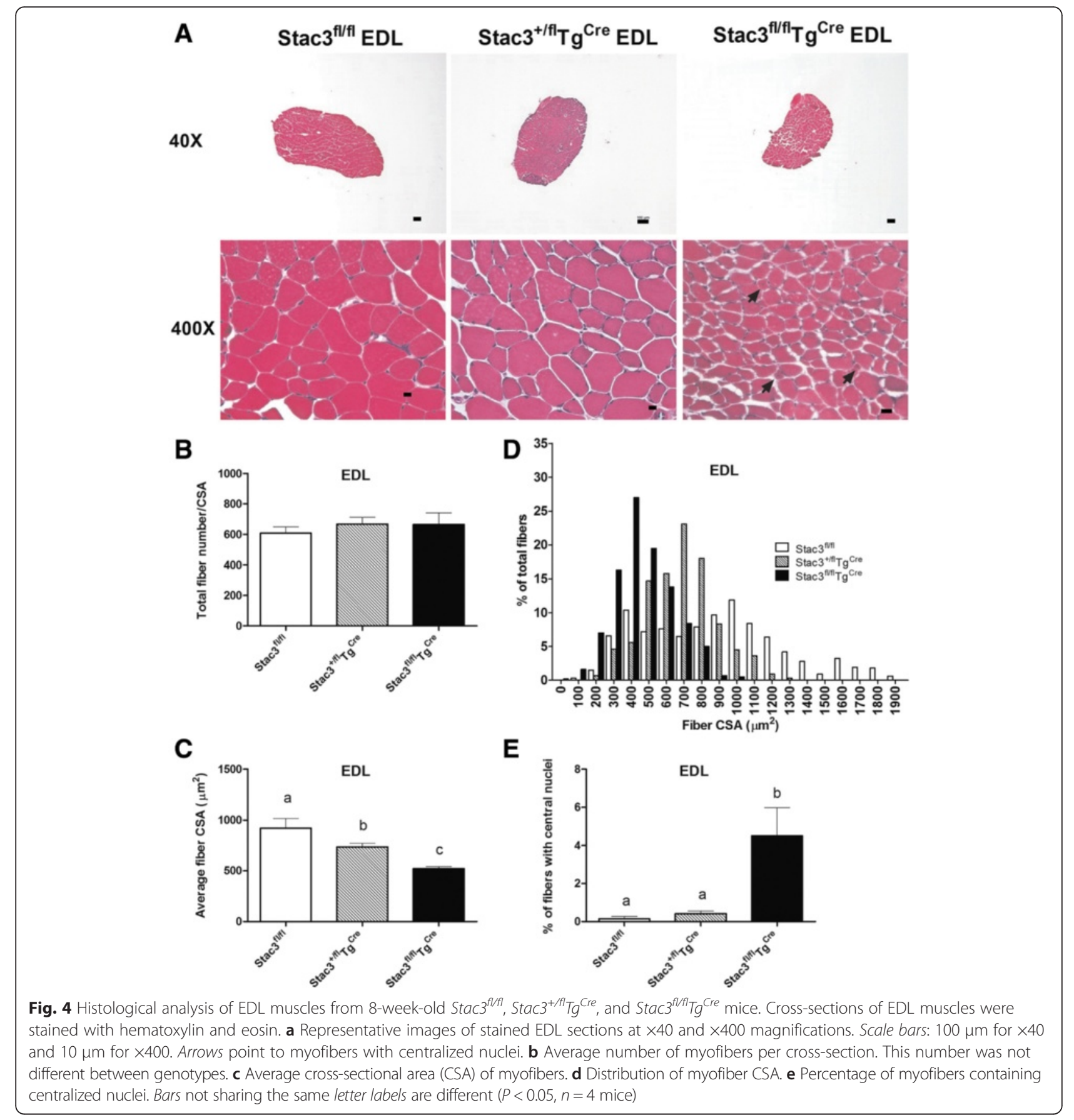

$S t a c 3^{f l f l}$ or $S t a c 3^{+f f l} T g$ Cre mice (Table 1). The Myh3 and Myh 8 genes are typically expressed in fetal and perinatal muscle or regenerating adult muscle [16, 17]. Both Myh3 and Myh8 mRNAs were expressed at greater levels in the 8-week-old $\mathrm{Stac}^{\text {fl/fl }} \mathrm{Tg}^{\mathrm{Cre}}$ than in the 8-week-old $\mathrm{Stac}^{\text {fl/fl }}$ or $\mathrm{Stac}^{+/ f l} \mathrm{Tg}^{\mathrm{Cre}}$ muscles (Table 1).

\section{Postnatal Stac3 deletion reduced muscle strength} $S t a c 3^{f l / f l} T g$ Cre mice had weaker grip strength than $S t a c 3^{f l / f l}$ mice at each of the 4 weeks following tamoxifen injection
(Fig. 9a, b, $P<0.05$ ). Stac $3^{+/ f l} T_{g}^{C r e}$ mice had weaker grip strength than $S t a c 3^{f l f l}$ mice at the first week after tamoxifen injection (Fig. 9a, b, $P<0.05)$. Compared to Stac ${ }^{f l / f l}$ mice, $S t a c 3^{f l f l} \mathrm{Tg}^{\mathrm{Cre}}$ mice had shorter grip time at the second, third, and fourth weeks after tamoxifen injection (Fig. 9c, d, $P<0.05)$. Stac3 ${ }^{+/ f l} \mathrm{Tg}^{\text {Cre }}$ mice had shorter grip time than $S t a c 3^{f l f l}$ mice at the fourth week after tamoxifen injection (Fig. 9a, b, P<0.05). Stac $3^{f l f l} \mathrm{Tg}^{\mathrm{Cre}}, \mathrm{Stac}^{+/ f l} \mathrm{Tg}$ Cre , and $S t a c 3^{f l f l}$ mice did not differ in grip strength or grip time at 4 weeks of age, i.e., before tamoxifen injection (Fig. 9a-d). 


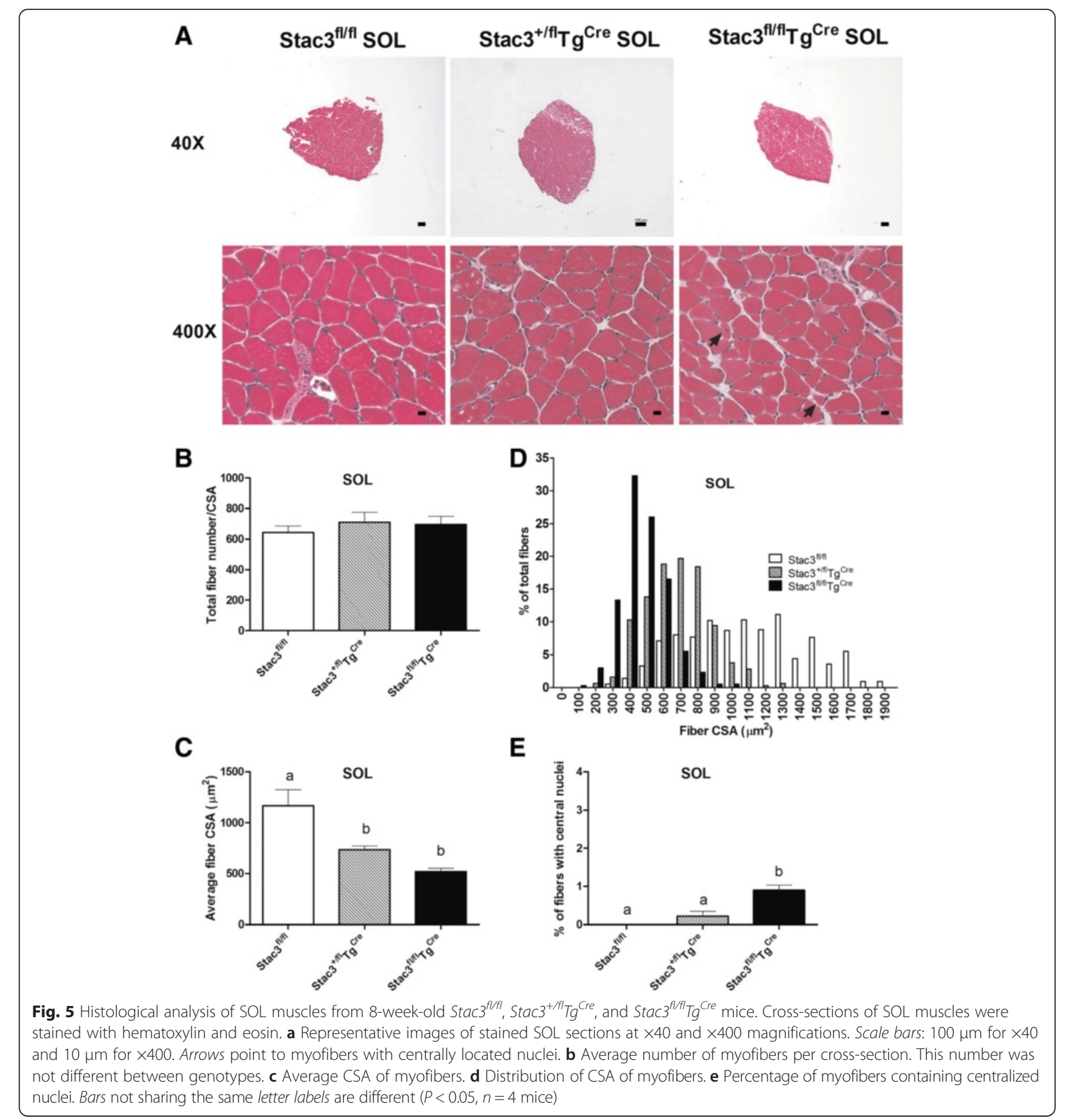

Postnatal Stac3 deletion reduced electrostimulation- but not caffeine-induced muscle contraction

We compared the contractile properties of the EDL and SOL muscles from $S t a c 3^{f l / f l}$ and $S t a c 3^{f l / f l} \mathrm{Tg}^{\mathrm{Cre}}$ mice at 8 weeks of age, i.e., 4 weeks after tamoxifen injection. The stress-frequency responses to electrostimulation were more than $50 \%$ smaller in the $S t a c 3^{f l / f l} \mathrm{Tg}^{\mathrm{Cre}}$ than in the $S t a c 3^{f l / f l}$ EDL and SOL muscles (Fig. 10a, b, $P<$ 0.05). However, for both twitch and tetanic $(150 \mathrm{~Hz})$ stresses, neither time to peak tension (TPT) nor halfrelaxation time (HRT) was different between the $S t a c 3^{f l / f l}$ $\mathrm{Tg}^{\mathrm{Cre}}$ and $\operatorname{Stac}{ }^{f l / f l}$ EDL or SOL muscle (Additional file 1: Table S2).

Caffeine induced both the EDL and SOL muscles from both 8-week-old $S t a c 3^{f l / f l}$ and $S t a c 3^{f l / f l} T g{ }^{C r e}$ mice to contract (Fig. 11a). However, the caffeine-induced maximum tension in either muscle was not different between the two genotypes (Fig. 11b). The TPT for caffeine-induced 


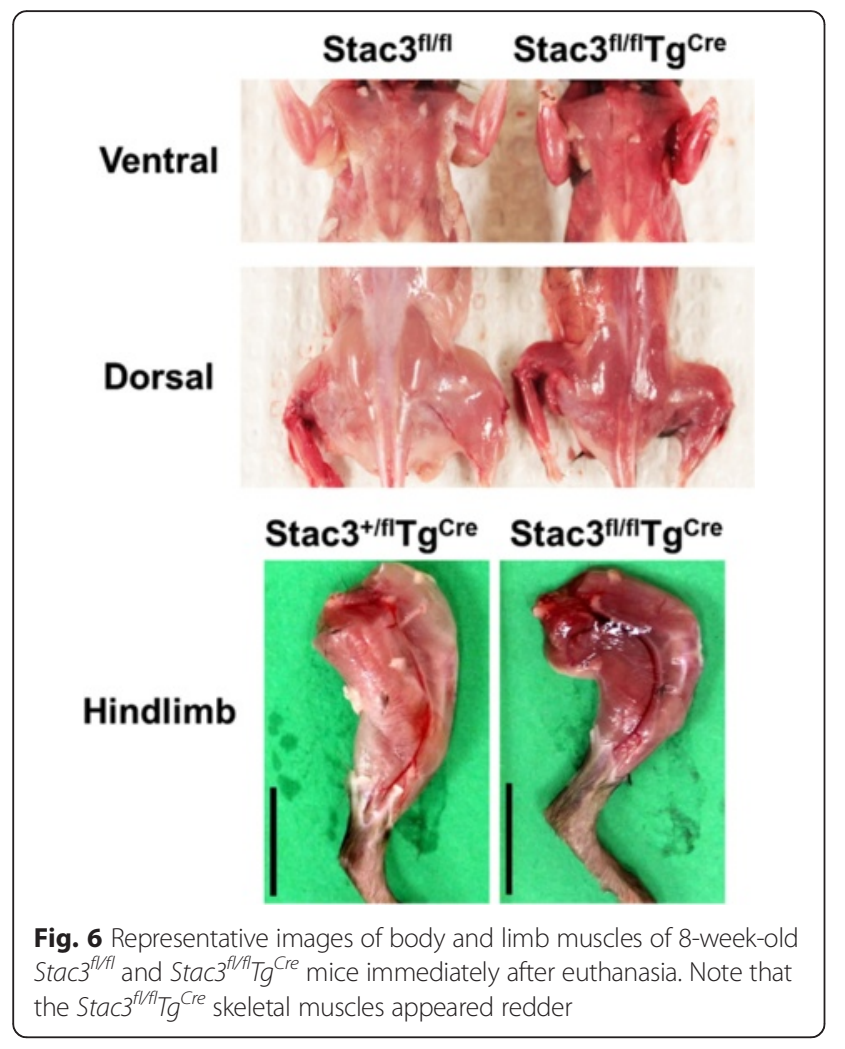

contraction in either muscle was also not different between the two genotypes (Additional file 1: Table S2).

Postnatal Stac3 deletion reduced electrostimulation- but not caffeine-induced intracellular increase of calcium in single myofibers

We compared electrostimulation-induced calcium release from the sarcoplasmic reticulum in single FDB myofibers from 8-week-old Stac $3^{f l / f l}$ and $S t a c 3^{f l / f l} T g$ Cre mice (Fig. 12a; Additional file 6: Figure S5). Resting concentration of intracellular calcium was $4 \%$ greater in $S t a c 3^{f l / f l} \mathrm{Tg}^{\mathrm{Cre}}$ than in $S t a c 3^{f l / f l}$ myofibers (Fig. 12b, $P<0.05)$. Frequent electrostimulation increased the concentration of intracellular calcium in both $S t a c 3^{f l / f l}$ and $S t a c 3^{f l / f l} \mathrm{Tg}^{\text {Cre }}$ myofibers (Fig. 12b), but the increase was smaller in $S t a c 3^{f l / f l} \mathrm{Tg}^{\mathrm{Cre}}$ than in $S t a c 3^{f l / f l}$ myofibers at each of the frequencies tested (Fig. 12b, $P<0.05$; Additional file 6: Figure S5). Caffeine caused an $8 \%$ increase in the concentration of intracellular calcium in resting $S t a c 3^{f l f l} \mathrm{Tg}^{\mathrm{Cre}}$ myofibers, but it had no effect on that in resting $S t a c 3^{f l f l}$ myofibers (Fig. 12c, P<0.05). Caffeine caused significant increases in the concentration of intracellular calcium in both $S t a c 3^{f l / f l}$ and $S t a c 3^{f l / f l} \mathrm{Tg}^{\mathrm{Cre}}$ myofibers that were electrically

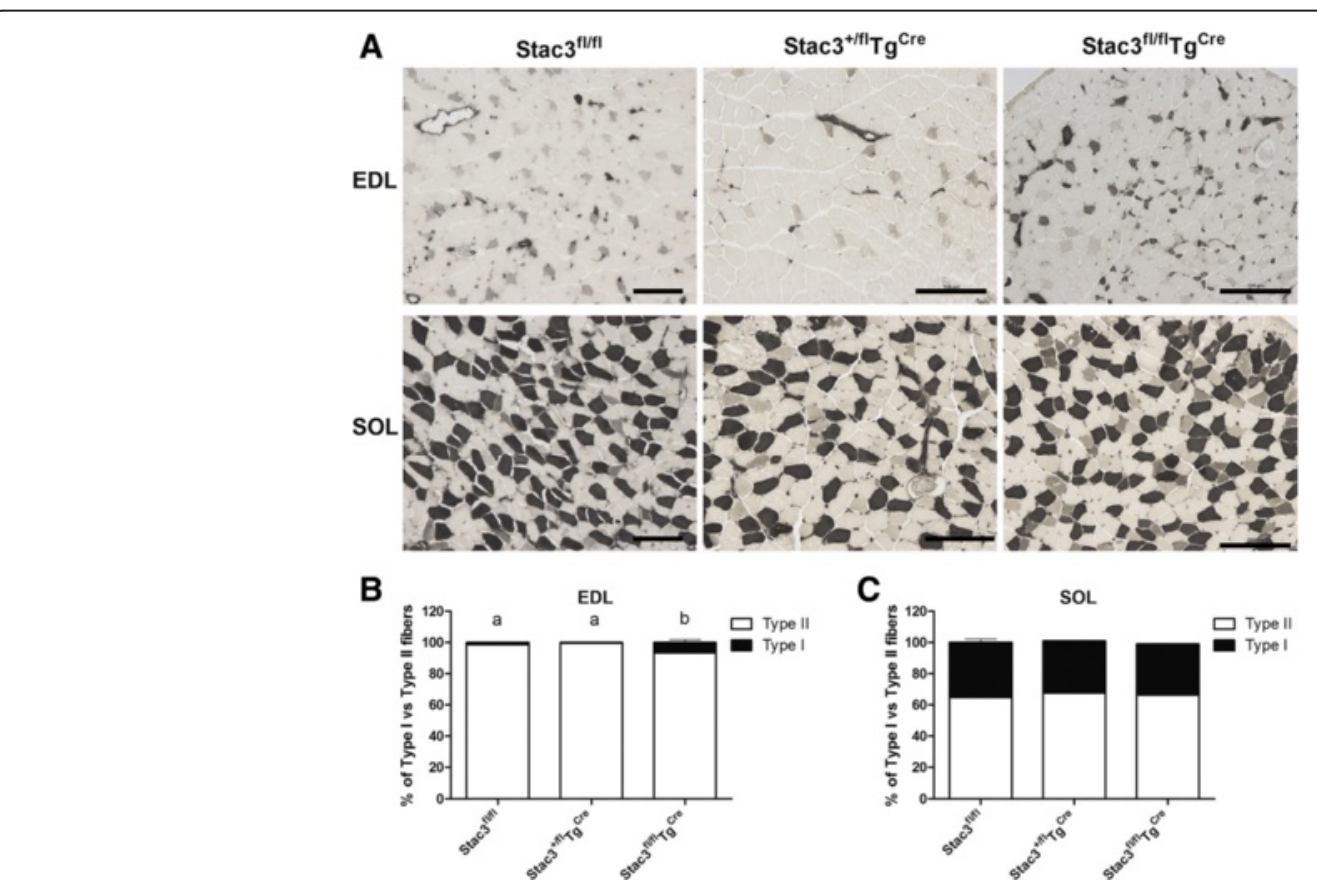

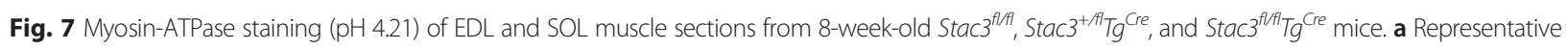
images of stained muscle sections. Scale bars: $100 \mu \mathrm{m}$. b Percentages of type I and type II myofibers in the EDL muscle. c Percentages of type I and type II myofibers in the SOL muscle. Values not sharing the same letter labels are different $(P<0.05, n=4$ mice) 


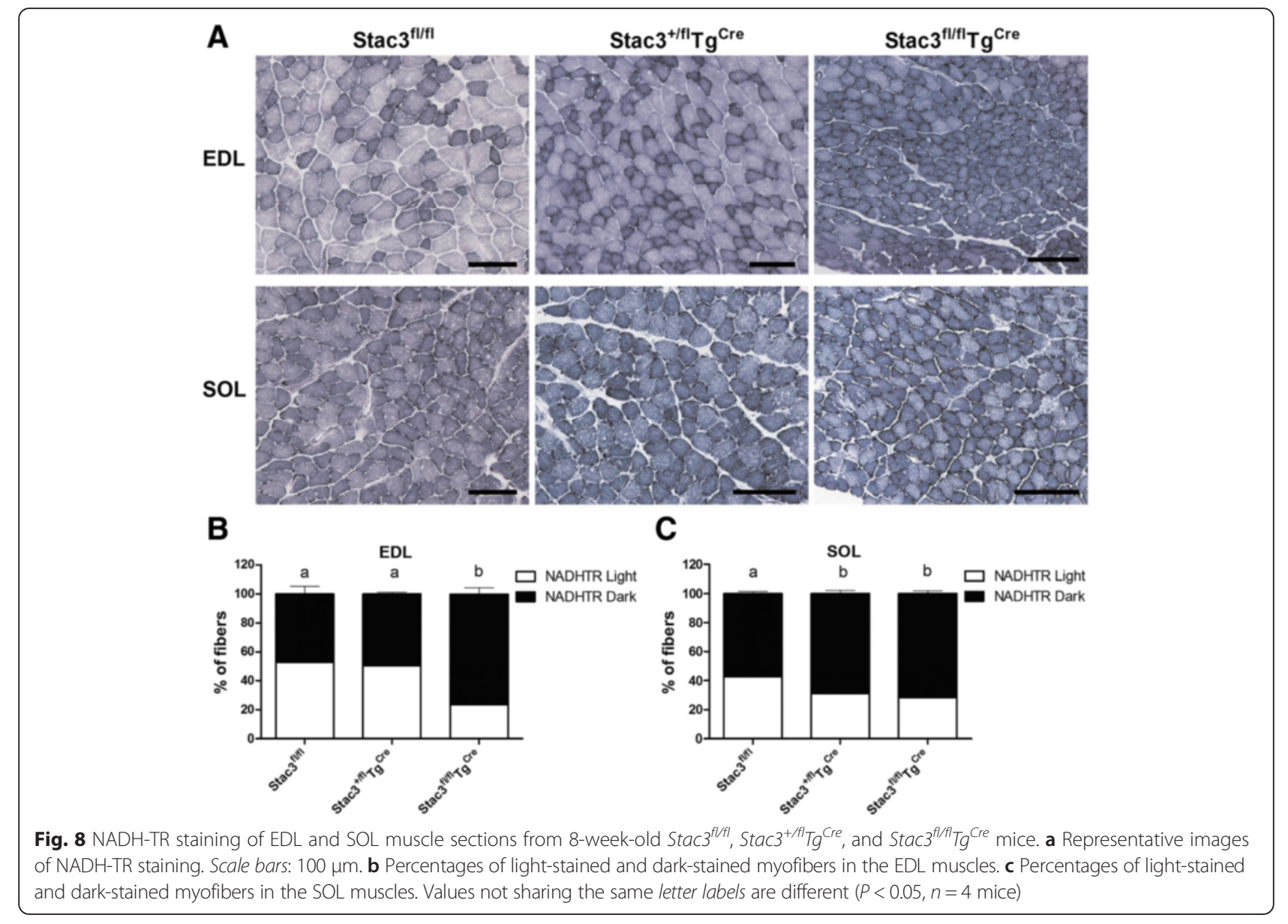

Table 1 Relative expression levels of selected mRNAs in left hindlimb muscles of mice 4 weeks after tamoxifen injection

\begin{tabular}{|c|c|c|c|c|}
\hline Gene & Fiber type & $\operatorname{Stac}^{f / f t}$ & $\mathrm{Stac3}^{+/ f I} \mathrm{Tg}^{\mathrm{Cre}}$ & $\mathrm{Stac}^{\mathrm{fl} / \mathrm{fl}} \mathrm{Tg}^{\mathrm{Cre}}$ \\
\hline Actn3 & $\|$ & $799.4 \pm 232.6^{a}$ & $6040.1 \pm 1281.6^{b}$ & $22679.4 \pm 4486.4^{c}$ \\
\hline Myh1 & $\|$ & $569.0 \pm 126.4^{\mathrm{a}}$ & $747.1 \pm 129.2^{\mathrm{ab}}$ & $1472.3 \pm 146.5^{b}$ \\
\hline Myh2 & $\|$ & $769.9 \pm 188.9$ & $1124.7 \pm 163.5$ & $1373.4 \pm 140.1$ \\
\hline Myh4 & $\|$ & $17463.2 \pm 976.8^{a}$ & $11812.9 \pm 1427.3^{\mathrm{ab}}$ & $8553.5 \pm 1702.5^{b}$ \\
\hline Tnnt3 & $\|$ & $104459.0 \pm 32168.1^{a}$ & $42788.0 \pm 7435.6^{\mathrm{b}}$ & $29655.8 \pm 4040.2^{b}$ \\
\hline$M b$ & । & $6.8 \pm 0.8^{\mathrm{a}}$ & $8.3 \pm 0.6^{\mathrm{ab}}$ & $10.2 \pm 0.4^{b}$ \\
\hline Mef2C & I & $1531.8 \pm 336.6^{\mathrm{a}}$ & $501.6 \pm 129.1^{b}$ & $898.8 \pm 69.1^{\mathrm{a}}$ \\
\hline Myh7 & I & $35.6 \pm 2.6^{a}$ & $42.1 \pm 9.0^{\mathrm{a}}$ & $85.6 \pm 9.9^{b}$ \\
\hline Ppargcla & I & $50.5 \pm 7.7^{a}$ & $136.8 \pm 35.2^{b}$ & $118.1 \pm 16.6^{b}$ \\
\hline Tnnt1 & I & $52.2 \pm 3.9^{a}$ & $70.5 \pm 21.0^{\mathrm{a}}$ & $155.3 \pm 16.1^{b}$ \\
\hline Myh3 & Fetal or regenerating & $1.3 \pm 0.5^{\mathrm{a}}$ & $0.7 \pm 0.1^{\mathrm{a}}$ & $39.1 \pm 10.8^{b}$ \\
\hline Myh8 & Perinatal or regenerating & $5.2 \pm 1.0^{\mathrm{a}}$ & $4.0 \pm 0.6^{a}$ & $12.2 \pm 2.6^{b}$ \\
\hline
\end{tabular}

Actn3 alpha actinin 3, Myh myosin heavy chain, Tnnt3 troponin T type 3, Mb myoglobin, Mef2c myocyte-specific enhancer factor 2C, Ppargc1a peroxisome proliferator-activated receptor gamma coactivator 1 alpha, Tnnt1 troponin T type 1. Data $=$ mean \pm SEM ( $n=4$ or 5 mice). a,b,c Values not sharing the same letter labels are different for the same gene $(P<0.05)$. 

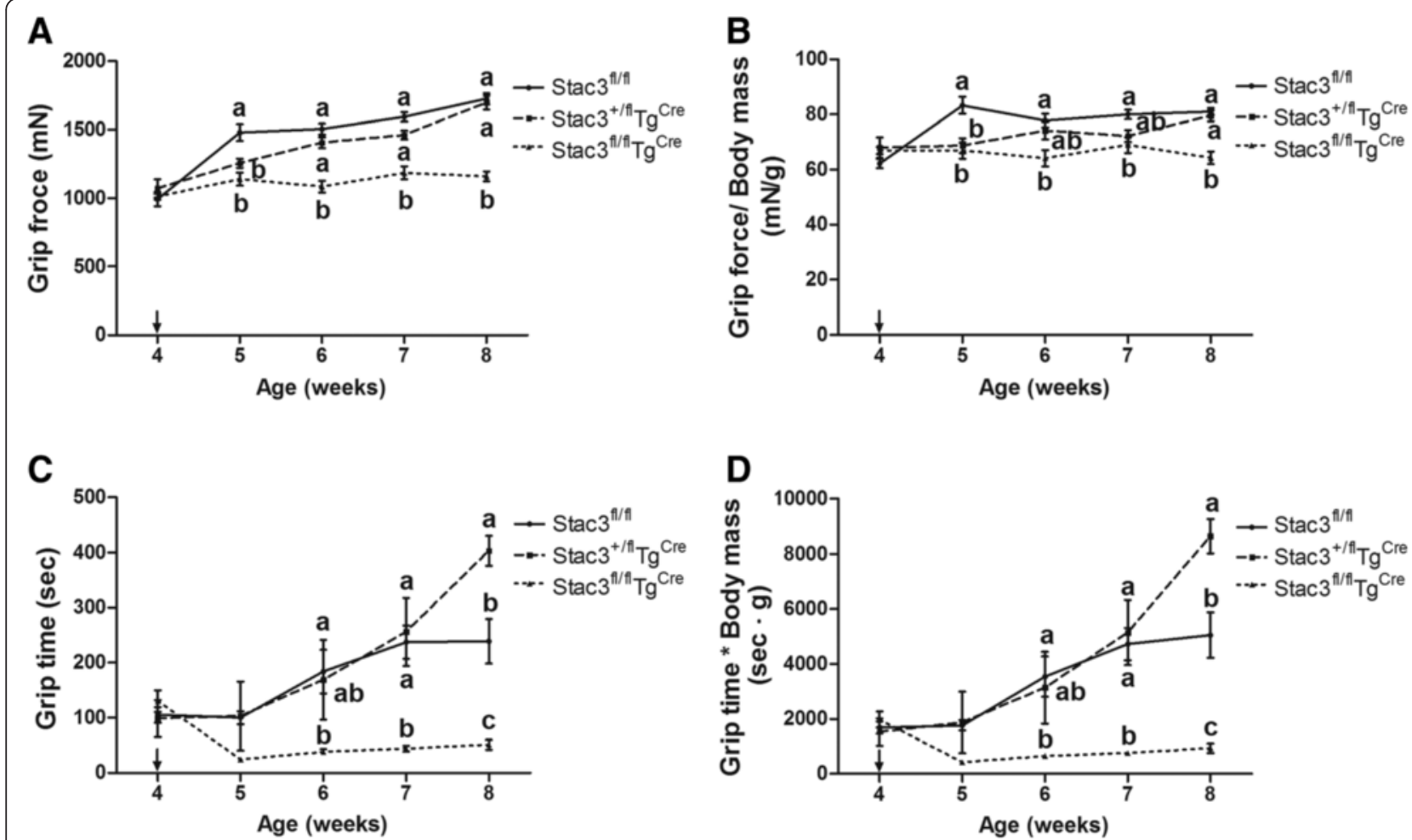

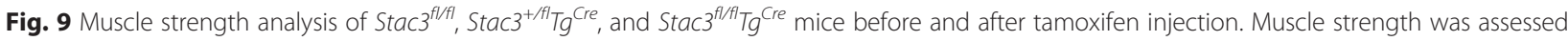
by grip strength and grip time tests at 4, 5, 6, 7, and 8 weeks of age. Mice received tamoxifen injection on the first 5 days of week 5 of age. a Grip strength. $\mathbf{b}$ Grip strength normalized to body mass. c Grip time. $\mathbf{d}$ Grip time normalized to body mass. Values not sharing the same letter labels are different at the same age $(P<0.05, n=4$ mice $)$

stimulated $(100 \mathrm{~Hz})$, but these increases were not different between the two genotypes (Fig. 12c).

\section{Postnatal Stac3 deletion reduced protein expression of RYR1 in skeletal muscle}

The DHPR $\alpha 1$ subunit CACNA1S (also known as Cav1.1) and RYR1 are essential for EC coupling. We compared the expression levels of these two proteins in hindlimb muscles from $\operatorname{Stac} 3^{f l / f l} \mathrm{Tg}^{\mathrm{Cre}}$ and $\operatorname{Stac} 3^{\text {fl/fl }}$ mice at 8 weeks of age, i.e., 4 weeks after tamoxifen injection, by western blotting analyses. The expression level of RYR1 was nearly $50 \%$ less in $\operatorname{Stac}^{f l / f l} \mathrm{Tg}^{\mathrm{Cre}}$ than in $\operatorname{Stac}^{\text {fl/fl}} \mathrm{Tg}^{\mathrm{Cre}}$ mice (Fig. 13, $P<0.05$ ). The expression level of CACNA1S was $30 \%$ less in $\operatorname{Stac}^{f l / f l} \mathrm{Tg}^{\mathrm{Cre}}$ than in $\mathrm{Stac}^{\mathrm{fl} / f l} \mathrm{Tg}^{\mathrm{Cre}}$ mice (Fig. 13, $P=0.10$ ).

\section{Discussion}

In this study, we characterized the effects of postnatal Stac3 deletion on skeletal muscle growth, fiber composition, and contractile responses in mice. We deleted the Stac3 gene in postnatal mice through the Flp-FRT and tamoxifen-inducible Cre-loxP recombination systems $[8,9]$. At the mRNA level, Stac3 expression in skeletal muscle was reduced to nearly none 4 weeks after tamoxifen injection. This low expression indicates that the floxed
Stac3 gene was efficiently excised by tamoxifen-induced Cre recombinase in skeletal muscle. However, at the protein level, STAC3 expression in skeletal muscle was reduced by $70 \% 4$ weeks after tamoxifen injection, which was less than that observed for Stac3 mRNA. This discrepancy was perhaps caused by the STAC3 protein being very stable or the translation of Stac3 mRNA into STAC3 protein being very efficient in mouse skeletal muscle. Nevertheless, the phenotypic changes in Stac3-deleted mice suggest that a $70 \%$ reduction in STAC3 protein expression is sufficient to alter the functions of this protein in mouse skeletal muscle.

Our data showed that postnatal Stac3 deletion caused several significant phenotypic changes in skeletal muscle. One change was reduced skeletal muscle growth. Histological analyses showed that the skeletal muscle of Stac3-deleted mice had a smaller CSA but a similar number of myofibers compared to that of control mice. These data suggest that STAC3 is needed for normal myofiber hypertrophy in postnatal mice. Myofiber hypertrophy results from increased protein synthesis and reduced protein degradation. The IGF1-IGFIR-PI3KAkt/PKB-mTOR and the myostatin-ACTRII-Smad2/3 are two primary signaling pathways that regulate protein accumulation, positively and negatively, respectively, in 


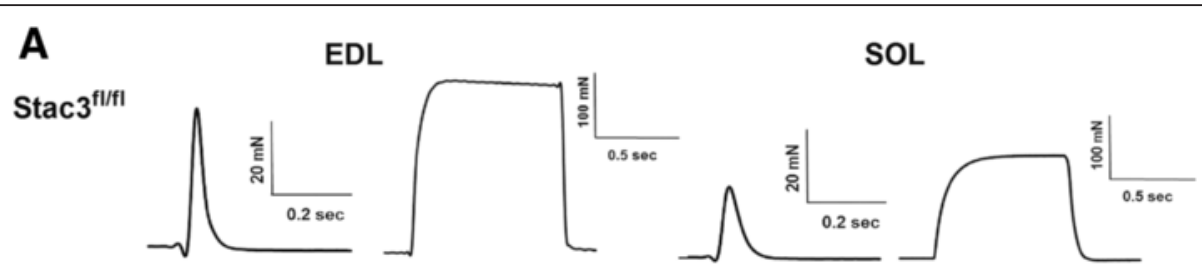

$\operatorname{Stac} 3^{\text {fl/fl }} \mathrm{Tg}^{\mathrm{Cre}}$

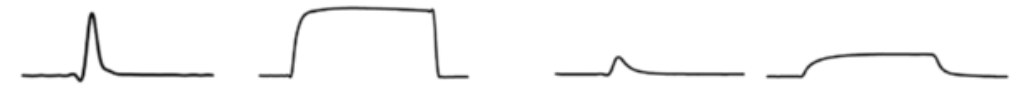

B
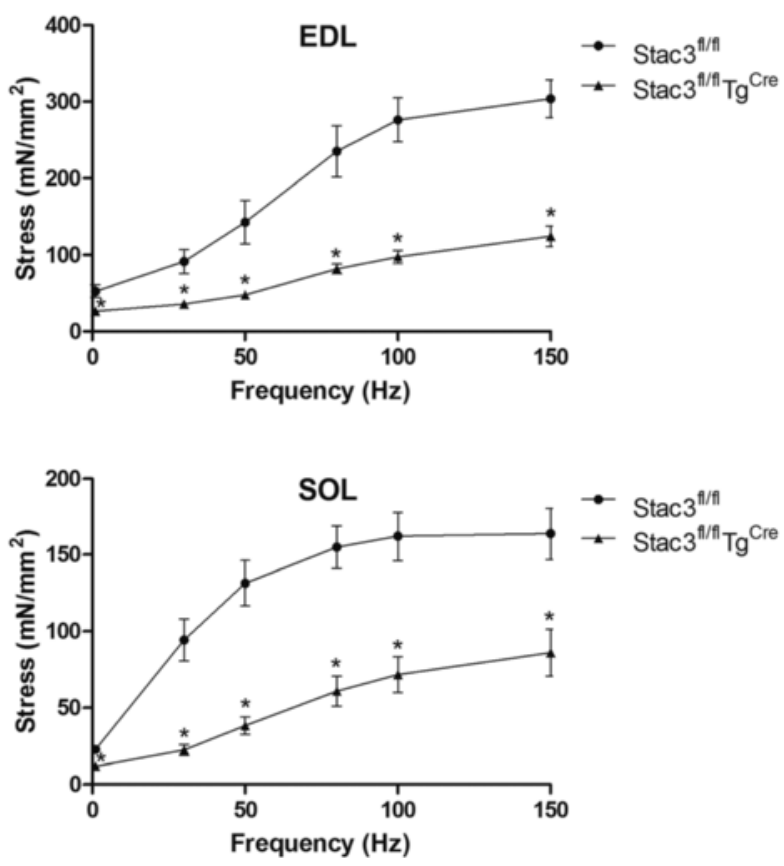

Fig. 10 Electrostimulation-induced contractions in EDL and SOL muscles from tamoxifen-injected Stac $3^{\mathrm{fl} / \mathrm{fl}}$ and $\mathrm{Stac}{ }^{\mathrm{fl} / \mathrm{fl}} \mathrm{Tg} \mathrm{g}^{\mathrm{Cre}}$ mice at 8 weeks of age. a Representative twitch $(1 \mathrm{~Hz})$ and tetanic $(150 \mathrm{~Hz})$ contractile responses. b Stress-frequency relationships. Frequencies of electrostimulation used were $1,30,50,80,100$, and $150 \mathrm{~Hz}$. Force was normalized to the average cross-sectional area of the muscle to yield stress $\left(\mathrm{mN} / \mathrm{mm}^{2}\right)$. Asterisks

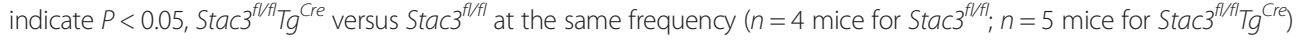

the skeletal muscle $[18,19]$. It remains to be determined if Stac3 deletion inhibits muscle hypertrophy by influencing these signaling pathways.

The second phenotypic change in Stac3-deleted muscle was an increased number of myofibers containing centralized nuclei. The histological analyses indicated that these centrally nucleated myofibers were among the smallest fibers in the muscles analyzed. Stac3-deleted skeletal muscle had an increased expression of Myh3 and Myh8 mRNAs. Since these two myosin heavy chain genes are typically expressed in fetal and neonatal muscle or regenerating adult muscle $[16,17]$, the increased myofibers with centralized nuclei in 8week-old Stac3-deleted mice represent either those from the fetal or neonatal stage or regenerating myofibers in adult muscle. Interestingly, embryonic Stac3 deletion caused the majority of myofibers in newborn mice to have centralized nuclei [1]. It remains to be determined if the increased myofibers with centralized nuclei in 8-week-old Stac3-deleted mice result from retarded myofiber growth or myofiber regeneration.

The third phenotypic change caused by postnatal Stac3 deletion was a muscle fiber-type switch. Postnatal Stac3 deletion increased the percentage of type I fibers in the fast twitch EDL muscle and the oxidative capacity in the slow twitch SOL muscle. Since Stac3 deletion did not alter the total number of myofibers in these muscles, the increase in type I or oxidative fibers suggests that Stac3 deletion inhibited the type I to type II transition in fast twitch muscle while stimulating the glycolytic to 

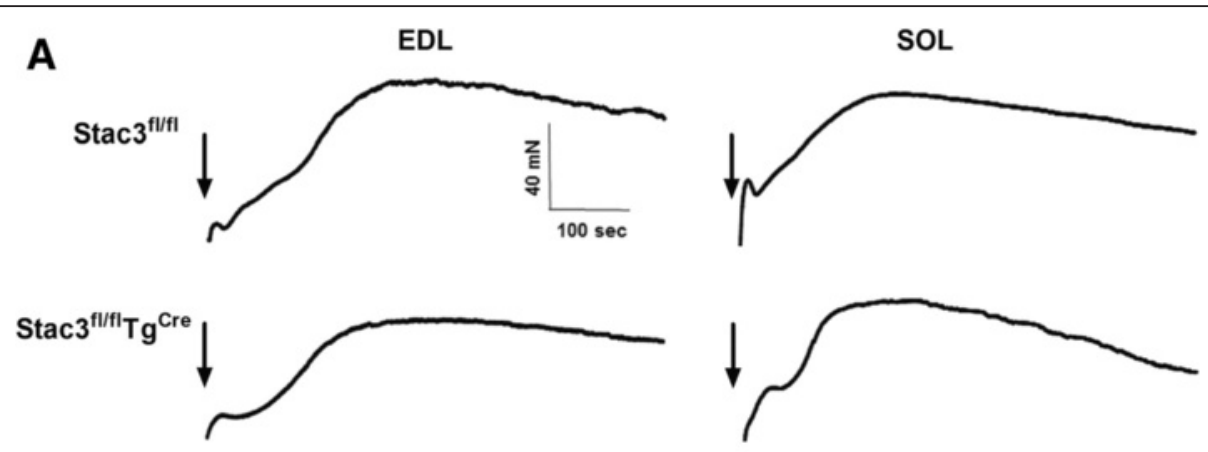

B
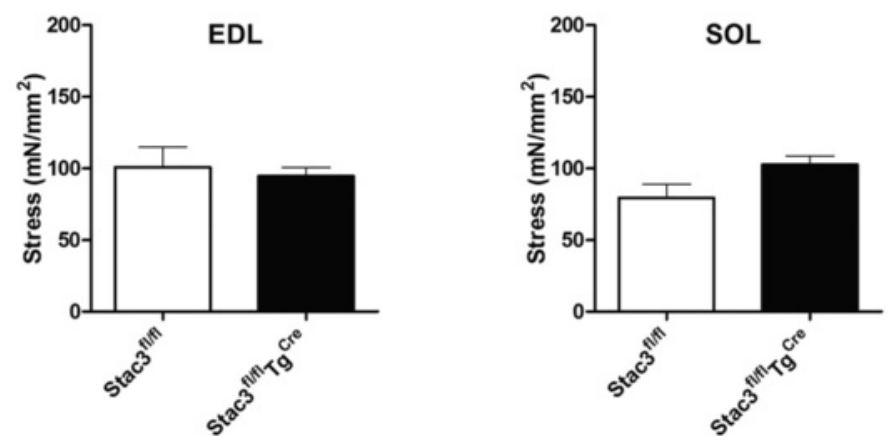

Fig. 11 Caffeine-induced contractions in EDL and SOL muscles from tamoxifen-injected Stac $3^{f / f l}$ and $S \operatorname{tac} 3^{f / f f l} T^{\text {Cre }}$ mice at 8 weeks of age. The EDL and SOL muscles from mice 4 weeks after tamoxifen injection were stimulated by $25 \mathrm{mM}$ caffeine. a Representative contractile responses. Black arrows indicate addition of caffeine. $\mathbf{b}$ Summary stress $(\mathrm{mN} / \mathrm{mm} 2)$ responses. Values are not different $(P>0.05)$ between Stac $3^{f / / f l}$ and

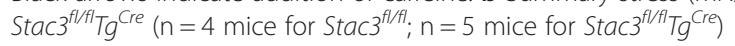

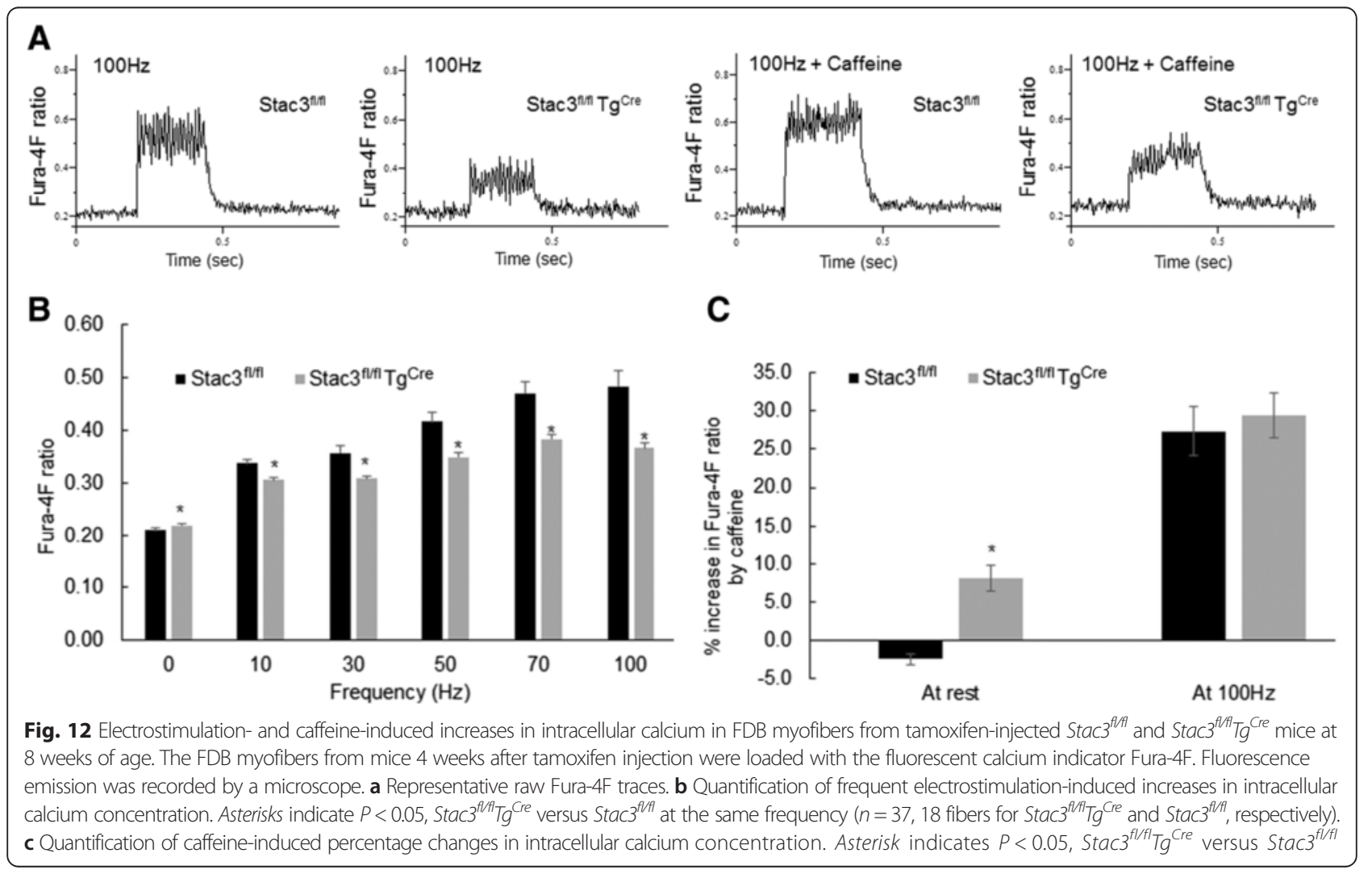




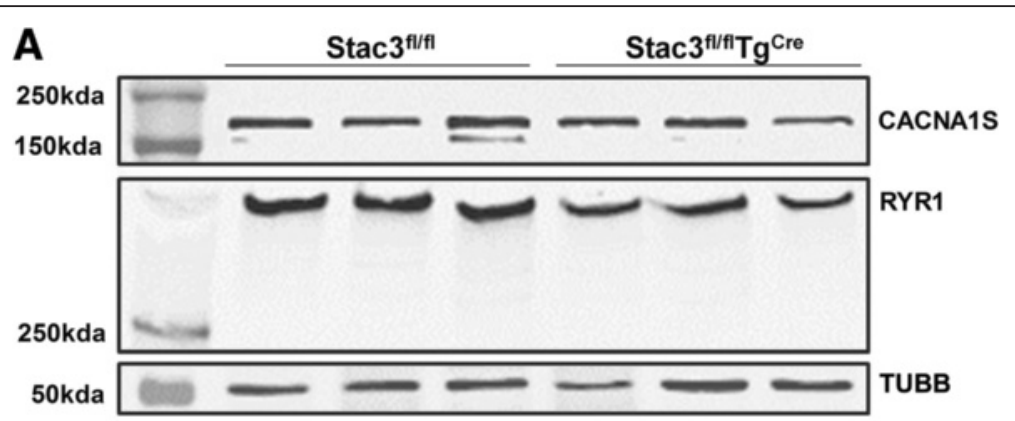

B
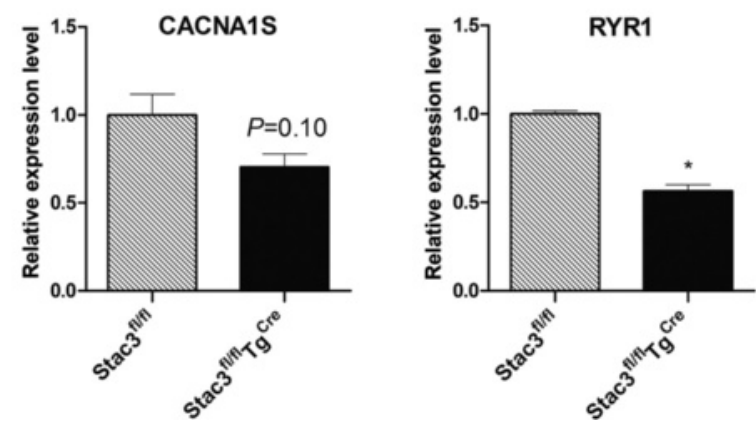

Fig. 13 Western blotting analyses of CACNA1S and RYR1 in hindlimb muscles from tamoxifen-injected StaC $3^{\text {ff/fl }}$ and Stac3 $3^{\text {fl/ff }} T^{\text {Cre }}$ mice at 8 weeks of age. a Representative western blots. Hindlimb muscles from three mice for each genotype were analyzed. Beta tubulin (TUBB) was detected as the loading control. Molecular markers are shown in the first lane. $\mathbf{b}$ Quantification of band intensities. Intensity of the CACNA1S or RYR1 band was normalized to that of the TUBB band in the same sample. Asterisk: $P<0.05$, Stac $3^{f / / f f} T^{C r e}$ versus Stac $3^{f / f l}$

oxidative fiber transition in slow twitch muscle. Such an effect of Stac3 deletion on fiber-type switch is supported by the facts that Stac3-deleted limb muscles in general had greater expression of genes marking type I fibers and less expression of genes marking type II fibers than control limb muscles and that Stac3-deleted muscles appeared redder and had greater expression of myoglobin mRNA than control muscles.

The fourth phenotypic change caused by postnatal Stac3 deletion in mice was reduced muscle force production. Both grip strength and grip time tests indicated that beginning the first week after tamoxifen injection, muscle strength was reduced in Stac3-deleted mice and that this reduction was not recovered 4 weeks after tamoxifen injection. Both grip strength and grip time in Stac3-deleted mice were less than those in control mice after being normalized to body mass. This data suggests the Stac3 deletion-caused reduction in muscle grip strength was not due to reduction in muscle size. Muscle contractile function tests showed that electrostimulation-induced maximum stress was smaller in Stac3-deleted compared to control muscle. Because stress was muscle force normalized to CSA, this data further suggested that the decreased muscle size was not responsible for the reduced contractile forces.

In this study, we found that postnatal Stac3 deletion reduced electrostimulation- but not caffeine-induced muscle contractions and calcium release from the sarcoplasmic reticulum (SR). This finding is consistent with earlier studies in Stac3-deleted mouse fetuses and Stac3-mutated zebrafish $[2,3]$. In this study, we found that the total cellular expression of RYR1 and, to a lesser degree, that of CACNA1S, were reduced in skeletal muscle of Stac3-deleted postnatal mice compared to control mice. Reduced expressions of CACNA1S and RYR1 were also observed in the skeletal muscle of Stac3-deleted fetal mice [2]. These observations suggest that Stac3 deletion might affect electrostimulation-induced calcium release from the SR and contraction in part by reducing the expression and/or the stability of RYR1 and CACNA1S proteins in the skeletal muscle. A recent study by Polster et al. demonstrates that STAC3 can target the DHPR $\alpha 1$ subunit CACNA1S to the plasma membrane of tsA201 cells [4]. In this study, we did not determine if Stac3-deleted skeletal muscle lacked CACNA1S on the sarcolemma or T-tubules, but a T-tubular deficiency of CACNA1S would explain why Stac3-deleted muscle was deficient in electrostimulation-induced calcium release from the SR and contraction. A sarcolemma-specific reduction of CACNA1S expression in adult mice has been shown to cause muscle atrophy without affecting EC coupling [20]. Thus, a sarcolemmal deficiency of CACNA1S expression would explain our observation that Stac3 deletion inhibited muscle hypertrophy in young mice. The 
attenuated muscle stress responses in Stac3-deleted muscle to electrostimulation could be also due to defective membrane depolarization, defective voltagedependent activation of DHPR, and/or deficient DHPR-RYR1 coupling. These possibilities remain to be characterized in the future. In this study, we also found that Stac3-deleted myofibers had a greater release of calcium from the SR in response to the ryanodine receptor agonist caffeine compared to control myofibers. This result suggests that Stac3 deletion might increase the sensitivity of RYR1 to caffeine or the amount of releasable calcium in the SR.

Muscle activity can affect both muscle size and fiber type $[21,22]$; thus, it is tempting to speculate that Stac3 deletion-induced changes in fiber size and type were secondary to changed muscle activity. Increased muscle activity generally contributes to fiber hypertrophy, whereas reduced muscle activity could result in muscle atrophy, perhaps through the calcium/calcineurin signaling pathway [23, 24]. As such, it is possible that Stac3 deletion-reduced muscle contraction is responsible for reduced fiber growth. However, the same mechanism may not be responsible for Stac3 deletioncaused type II to type I fiber transformation because reduced muscle activity usually leads to type I to type II fiber switch [25]. The STAC3 protein contains a SH3 domain, and through this domain, STAC3 could interact with and affect the expression, location, or function of many proteins [26]. Therefore, it is possible that STAC3 mediates EC coupling, fiber-type switch, and fiber hypertrophy through different protein partners.

\section{Conclusions}

This study demonstrates that Stac3 is important to fiber growth, fiber-type composition, contractile responses, and electrostimulation-induced release of calcium ions from the sarcoplasmic reticulum in postnatal skeletal muscle and that the role of STAC3 in skeletal muscle may be beyond the process of EC coupling. Since Stac3 knockout is embryonically lethal, the postnatal Stac3 knockout mouse generated in the present study will be a more convenient model for understanding the role of STAC3 in skeletal muscle physiology and disease and the underlying cellular and molecular mechanisms.

\section{Additional files}

Additional file 1: Table S1. Nucleotide sequences of primers used in this study. Table S2. Contractile properties of EDL and SOL muscles from 8-week-old Stac3 ${ }^{f / / f l}$ and Stac3 $^{f / / f f} \mathrm{Tg}^{\text {Cre }}$ mice. (DOCX $18 \mathrm{~kb}$ )

Additional file 2: Figure S1. Histological analysis of EDL muscles from 4-week-old $\mathrm{StaC}^{\mathrm{fl} / \mathrm{fl}}, \mathrm{StaC}^{+/ f f} \mathrm{Tg}^{\mathrm{Cre}}$, and $\mathrm{StaC} 3^{\mathrm{fl} / f l} \mathrm{Tg}^{\mathrm{Cre}}$ mice. Cross-sections of EDL muscles were stained with hematoxylin and eosin. a Representative images of stained EDL sections at $\times 40$ and $\times 400$ magnifications. Scale bars: $100 \mu \mathrm{m}$ for $\times 40$ and $10 \mu \mathrm{m}$ for $\times 400$. Arrows point to myofibers with centralized nuclei. $\mathbf{b}$ Average number of myofibers per cross-section. This number was not different between genotypes. c Average cross-sectional area (CSA) of myofibers. $\mathbf{d}$ Distribution of CSA of myofibers. e Percentage of myofibers containing centralized nuclei. (TIF $74102 \mathrm{~kb}$ )

Additional file 3: Figure S2. Histological analysis of SOL muscles from 4-week-old Stac3 ${ }^{f / / f l}, \mathrm{Stac}^{+/ f l} \mathrm{Tg}^{\mathrm{Cre}}$, and $\mathrm{Stac} 3^{f / / f l} \mathrm{Tg}^{\mathrm{Cre}}$ mice. Cross-sections of SOL muscles were stained with hematoxylin and eosin. a Representative images of stained SOL sections at $\times 40$ and $\times 400$ magnifications. Scale bars: $100 \mu \mathrm{m}$ for $\times 40$ and $10 \mu \mathrm{m}$ for $\times 400$. Arrows point to myofibers with centrally located nuclei. $\mathbf{b}$ Average number of myofibers per cross-section. This number was not different between genotypes. c Average cross-sectional area (CSA) of myofibers. $\mathbf{d}$ Distribution of CSA of myofibers. e Percentage of myofibers containing centralized nuclei. (TIF 73696 kb)

Additional file 4: Figure S3. Myosin-ATPase staining ( $\mathrm{pH} 4.21$ ) of crosssections of EDL and SOL muscles from 4-week-old $\mathrm{Stac3}^{\mathrm{fl} / \mathrm{fl}}$, $\mathrm{Stac}^{+/ / f l} \mathrm{Tg}^{\mathrm{Cre}}$, and $\mathrm{StaC}^{\mathrm{f} / \mathrm{f}} \mathrm{Tg} \mathrm{Cre}^{\mathrm{Cre}}$ mice before tamoxifen injection. a Representative images of stained muscle sections. Scale bars: $100 \mu \mathrm{m}$. b Percentages of type I and type II myofibers in EDL muscles. c Percentages of type I and type I| myofibers in SOL muscles. None of the percentages are different between genotypes ( $n=4$ mice). (TIF $50091 \mathrm{~kb}$ )

Additional file 5: Figure S4. NADH-TR staining of cross-sections of EDL and SOL muscles from 4-week-old Stac3 ${ }^{f / / f l}, \mathrm{Stac}^{+/ f f} \mathrm{Tg}^{\mathrm{Cre}}$, and $\mathrm{Stac}{ }^{f / / f l} \mathrm{Tg}^{\mathrm{Cre}}$ mice before tamoxifen injection. a Representative images of NADH-TR staining. Scale bars: $100 \mu \mathrm{m}$. b Percentages of light-stained and dark-stained myofibers in EDL muscles. c Percentages of light-stained and dark-stained myofibers in SOL muscles. None of the percentages are different between genotypes ( $n=4$ mice). (TIF $51536 \mathrm{~kb}$ )

Additional file 6: Figure S5. Quantification of electrostimulationinduced increases in intracellular calcium concentration in FDB myofibers from tamoxifen-injected $S \operatorname{tac} 3^{f / / f l}$ and $S \operatorname{tac} 3^{f / / f l} \mathrm{Tg}^{\text {Cre }}$ mice at 8 weeks of age The FDB myofibers from mice 4 weeks after tamoxifen injection were loaded with the fluorescent calcium indicator Fura-2. Fluorescence emission was recorded by a microscope. Asterisks indicate $P<0.05$, Stac $3^{f / f f} \mathrm{Tg}^{\text {Cre }}$ versus $\mathrm{Stac}^{\mathrm{fl} / \mathrm{fl}}$ at the same frequency ( $n=8$ fibers each genotype). (TIF $9896 \mathrm{~kb}$ )

\section{Abbreviations}

Actn3: alpha actinin 3; CACNA1S (also known as Cav1.1): calcium channel, voltage-dependent, L-type, alpha 1S subunit; CSA: cross-sectional area; DHPR: dihydropyridine receptor; DHPRa1s: dihydropyridine receptor, alpha $1 \mathrm{~S}$ subunit; EC: excitation-contraction; EDL: extensor digitorum longus; FBS: fetal bovine serum; FDB: flexor digitorum brevis; Flp: flippase; FRT: flippase recognition target; HRT: half-relaxation time; $M b$ : myoglobin; Mef2c: myocytespecific enhancer factor 2C; mTOR: mammalian target of rapamycin; Myh: myosin heavy chain; NADH-TR: nicotinamide adenine dinucleotidetetrazolium reductase; Ppargcla: peroxisome proliferator-activated receptor gamma coactivator 1 alpha; PSS: physiological salt solution; RIPA: radio immunoprecipitation assay; RT-qPCR: reverse transcription-quantitative polymerase chain reaction; RYR: ryanodine receptor; SOL: soleus; Stac3: SH3 and cysteine-rich domain 3; TA: tibialis anterior; Tnnt1: troponin T type 1; Tnnt3: troponin T type 3; TPT: time to peak tension; TUBB: beta tubulin.

\section{Competing interests}

The authors declare that they have no competing interests.

\section{Authors' contributions}

XC performed all experiments, analyzed data, and drafted the manuscript; JD performed the muscle contraction experiments and analyzed data; DAGM performed the calcium imaging experiments and analyzed data; ERC designed the calcium imaging experiments, interpreted results, and revised the manuscript; RWG designed the muscle contraction experiments, interpreted results, and revised the manuscript; $\mathrm{HJ}$ conceived the project, designed experiments, interpreted results, and wrote the manuscript. All authors read and approved the final manuscript.

\section{Author details}

${ }^{1}$ Department of Animal and Poultry Sciences, Virginia Tech, Blacksburg, VA, USA ²Department of Human Nutrition, Foods, and Exercise, Virginia Tech, Blacksburg, VA, USA. ${ }^{3}$ Department of Kinesiology, School of Public Health, University of Maryland, College Park, MD, USA. 
Received: 3 February 2016 Accepted: 30 March 2016

Published online: 11 April 2016

\section{References}

1. Reinholt BM, Ge X, Cong X, Gerrard DE, Jiang H. Stac3 is a novel regulator of skeletal muscle development in mice. PLoS One. 2013;8(4):e62760.

2. Nelson BR, Wu F, Liu Y, Anderson DM, McAnally J, Lin W, Cannon SC, Bassel-Duby R, Olson EN. Skeletal muscle-specific T-tubule protein STAC3 mediates voltage-induced $\mathrm{Ca} 2+$ release and contractility. Proc Natl Acad Sci U S A. 2013;110(29):11881-6.

3. Horstick EJ, Linsley JW, Dowling JJ, Hauser MA, McDonald KK, Ashley-Koch A, Saint-Amant L, Satish A, Cui WW, Zhou W, et al. Stac3 is a component of the excitation-contraction coupling machinery and mutated in Native American myopathy. Nat Commun. 2013;4:1952.

4. Polster A, Perni S, Bichraoui H, Beam KG. Stac adaptor proteins regulate trafficking and function of muscle and neuronal L-type Ca2+ channels. Proc Natl Acad Sci U S A. 2015;112(2):602-6.

5. Ge X, Zhang Y, Park S, Cong X, Gerrard DE, Jiang H. Stac3 inhibits myoblast differentiation into myotubes. PLoS One. 2014;9(4):e95926.

6. Zhang $Y$, Cong $X$, Wang A, Jiang $H$. Identification of the STAC3 gene as a skeletal muscle-specifically expressed gene and a novel regulator of satellite cell differentiation in cattle. J Anim Sci. 2014;92(8):3284-90.

7. Dowling JJ, Lillis S, Amburgey K, Zhou HY, Al-Sarraj S, Buk SJA, Wraige E, Chow G, Abbs S, Leber S, et al. King-Denborough syndrome with and without mutations in the skeletal muscle ryanodine receptor (RYR1) gene. Neuromuscul Disord. 2011:21(6):420-7.

8. Hayashi S, McMahon AP. Efficient recombination in diverse tissues by a tamoxifen-inducible form of Cre: a tool for temporally regulated gene activation/inactivation in the mouse. Dev Biol. 2002;244(2):305-18.

9. Rodriguez Cl, Buchholz F, Galloway J, Sequerra R, Kasper J, Ayala R, Stewart AF, Dymecki SM. High-efficiency deleter mice show that FLPe is an alternative to Cre-loxP. Nat Genet. 2000;25(2):139-40.

10. Beedle AM, Turner AJ, Saito Y, Lueck JD, Foltz SJ, Fortunato MJ, Nienaber PM, Campbell KP. Mouse fukutin deletion impairs dystroglycan processing and recapitulates muscular dystrophy. J Clin Invest. 2012;122(9):3330-42.

11. Livak KJ, Schmittgen TD. Analysis of relative gene expression data using real-time quantitative PCR and the 2(T)(-Delta Delta C) method. Methods. 2001;25(4):402-8.

12. Suga T, Kimura E, Morioka Y, Ikawa M, Li S, Uchino K, Uchida Y, Yamashita S, Maeda Y, Chamberlain JS, et al. Muscle fiber type-predominant promoter activity in lentiviral-mediated transgenic mouse. PLoS One. 2011;6(3):e16908

13. Wolff AV, Niday AK, Voelker KA, Call JA, Evans NP, Granata KP, Grange RW. Passive mechanical properties of maturing extensor digitorum longus are not affected by lack of dystrophin. Muscle Nerve. 2006;34(3):304-12.

14. Grange RW, Gainer TG, Marschner KM, Talmadge RJ, Stull JT. Fast-twitch skeletal muscles of dystrophic mouse pups are resistant to injury from acute mechanical stress. Am J Physiol Cell Physiol. 2002;283(4):C1090-101.

15. Chin ER, Allen DG. The contribution of pH-dependent mechanisms to fatigue at different intensities in mammalian single muscle fibres. J Physiol. 1998:512(Pt 3):831-40

16. Handschin C, Chin S, Li P, Liu F, Maratos-Flier E, Lebrasseur NK, Yan Z, Spiegelman BM. Skeletal muscle fiber-type switching, exercise intolerance, and myopathy in PGC-1alpha muscle-specific knock-out animals. J Biol Chem. 2007;282(41):30014-21.

17. Schiaffino S, Rossi AC, Smerdu V, Leinwand LA, Reggiani C. Developmental myosins: expression patterns and functional significance. Skelet Muscle. 2015;5:22.

18. Schiaffino S, Dyar KA, Ciciliot S, Blaauw B, Sandri M. Mechanisms regulating skeletal muscle growth and atrophy. FEBS J. 2013;280(17):4294-314.

19. Egerman MA, Glass DJ. Signaling pathways controlling skeletal muscle mass. Crit Rev Biochem Mol Biol. 2014;49(1):59-68.

20. Pietri-Rouxel F, Gentil C, Vassilopoulos S, Baas D, Mouisel E, Ferry A, Vignaud A, Hourde C, Marty I, Schaeffer L, et al. DHPR alpha1S subunit controls skeletal muscle mass and morphogenesis. EMBO J. 2010;29(3):643-54.

21. Zierath JR, Hawley JA. Skeletal muscle fiber type: influence on contractile and metabolic properties. PLoS Biol. 2004;2(10):e348.

22. Schiaffino S, Reggiani C. Fiber types in mammalian skeletal muscles. Physiol Rev. 2011;91(4):1447-531.

23. Goldberg AL, Etlinger JD, Goldspink DF, Jablecki C. Mechanism of workinduced hypertrophy of skeletal muscle. Med Sci Sports. 1975;7(3):185-98.
24. Bonaldo P, Sandri M. Cellular and molecular mechanisms of muscle atrophy. Dis Model Mech. 2013;6(1):25-39.

25. Lin J, Wu H, Tarr PT, Zhang CY, Wu Z, Boss O, Michael LF, Puigserver P, Isotani E, Olson EN, et al. Transcriptional co-activator PGC-1 alpha drives the formation of slow-twitch muscle fibres. Nature. 2002;418(6899):797-801.

26. Suzuki H, Kawai J, Taga C, Yaoi T, Hara A, Hirose K, Hayashizaki Y, Watanabe S. Stac, a novel neuron-specific protein with cysteine-rich and $\mathrm{SH} 3$ domains. Biochem Biophys Res Commun. 1996;229(3):902-9.

\section{Submit your next manuscript to BioMed Central and we will help you at every step:}

- We accept pre-submission inquiries

- Our selector tool helps you to find the most relevant journal

- We provide round the clock customer support

- Convenient online submission

- Thorough peer review

- Inclusion in PubMed and all major indexing services

- Maximum visibility for your research

Submit your manuscript at www.biomedcentral.com/submit
Biomed Central 